\title{
Toward system-level understanding of baculovirus-host cell interactions: from molecular fundamental studies to large-scale proteomics approaches
}

\author{
Francisca Monteiro ${ }^{1,2}$, Nuno Carinhas ${ }^{1,2}$, Manuel J. T. Carrondo ${ }^{1,2,3}$, Vicente Bernal ${ }^{4}$ * \\ and Paula M. Alves ${ }^{1,2}$ * \\ 'Animal Cell Technology Unit, Instituto de Biologia Experimental e Tecnológica, Oeiras, Portugal \\ ${ }^{2}$ Animal Cell Technology Unit, Instituto de Tecnologia Quimica e Biológica, Oeiras, Portugal \\ ${ }^{3}$ Departamento de Química, Faculdade de Ciências e Tecnologia, Universidade Nova de Lisboa, Caparica, Portugal \\ ${ }^{4}$ Departamento de Bioquímica y Biología Molecular B e Inmunología, Facultad de Química, Regional Campus of International Excellence \\ "Campus Mare Nostrum," Universidad de Murcia, Murcia, Spain
}

\section{Edited by:}

Kevin Coombs, University of

Manitoba, Canada

\section{Reviewed by:}

Hsei-Wei Wang, National Yang Ming

University, Taiwan

Peter Krell, University of Guelph

Canada

\section{*Correspondence:}

Vicente Bernal, Departamento de Bioquímica y Biología Molecular B e Inmunología, Facultad de Química, Regional Campus of International Excellence "Campus Mare Nostrum," Universidad de Murcia,

30100 Murcia, Spain.

e-mail:vbernal@um.es;

Paula M. Alves, Animal Cell

Technology Unit, Instituto de Biologia

Experimental e Tecnológica and

Instituto de Tecnologia Quimica e

Biológica, Apartado 12, 27801-901

Oeiras, Portugal.

e-mail:marques@itab.unl.pt
Baculoviruses are insect viruses extensively exploited as eukaryotic protein expression vectors. Molecular biology studies have provided exciting discoveries on virus-host interactions, but the application of omic high-throughput techniques on the baculovirus-insect cell system has been hampered by the lack of host genome sequencing. While a broader, systems-level analysis of biological responses to infection is urgently needed, recent advances on proteomic studies have yielded new insights on the impact of infection on the host cell. These works are reviewed and critically assessed in the light of current biological knowledge of the molecular biology of baculoviruses and insect cells.

Keywords: baculovirus, virus-host interactions, cytoskeleton, apoptosis, stress response, proteomics

\section{BRIEF INTRODUCTION TO THE BACULOVIRUS-INSECT CELL SYSTEM}

Baculoviruses are rod-shaped viruses with double-stranded DNA genomes. They infect arthropods, mainly insects, a feature that encouraged their usage as ecologically friendly biopesticides (Miller, 1997). Later on, baculoviruses started to be exploited as viral vectors for eukaryotic protein expression, which quickened the pace of their characterization at the cellular and molecular levels (Possee, 1993). The best-studied member of this family, Autographa californica multicapsid nucleopolyhedrovirus (AcMNPV), encodes for 150 genes and has its own genome completely sequenced. The cell lines used for AcMNPV propagation are derived from the pupal ovarian tissue of the fall armyworm Spodoptera frugiperda, being the $S f 9$ clonal isolate the most frequently used. Insect cells possess several advantages as protein expression factories. They grow in suspension without serum supplementation, are able to perform post-translational modifications and the scale-up of cultures is quite straightforward (Ikonomou etal., 2003). However, the production potential of insect cells has been hampered by the so called "cell density effect," i.e., the drop in specific productivity when cells are infected with baculovirus at high cell concentration. As $S f 9$ cells attain high densities, central metabolism suffers a general down-regulation (Bernal et al., 2009). Viral infection induces a multi-level response in the host, during which a vast number of intracellular pathways are activated/deactivated (i.e., regulated) and profound metabolic changes occur. These changes are ultimately responsible for the production performance of the system. A deeper understanding of such phenomena will certainly allow for the rational design of strategies for bioprocess optimization. The genome of $S$. frugiperda remains unsequenced, which limits the extent to which highthroughput (genome-scale) technologies can be applied. To date, only few proteomic-based high-throughput studies concerning the impact of baculovirus infection on their host cells have been pursued. The aim of this review is to summarize the state of the art in the molecular biology of the baculovirus replication and host-virus interaction in this system. The implications of these mechanisms for proper infection and their potential use for the improvement of baculoviruses-based applications such as protein production and use as gene therapy vectors will be highlighted. 


\section{BACULOVIRUS LIFE CYCLE: FROM IN VIVO TO IN VITRO CULTURES}

Baculoviruses have a biphasic replication cycle in the insect host, involving the formation of two types of virions which are produced in different phases of the infection process and have different roles: the occlusion-derived virions (ODVs), adapted for stability outside the insect host, and the budded virions (BVs), non-occluded and responsible for the systemic, cell-to-cell dissemination of the virus within the insect. Specific roles, morphology, and functionality of both virion types are described in more detail below. Moreover, the virus life cycle is temporally divided into three consecutive phases (immediate-early/early; late and very late) regarding gene expression programming (Passarelli and Guarino, 2007). Specific constraints and events of each phase are summarized along the text.

Baculovirus infection starts when insect larvae ingest the occlusion bodies (Keddie et al., 1989). These are forms resistant to environmental factors. ODVs are embedded in a proteinaceous matrix mostly composed of the very late expressed protein polyhedrin. When facing the alkaline conditions in the insect midgut, the occlusion body dissolves and releases the ODVs, and the polyhedrin matrix is in turn degraded by proteinases present in the gut or associated with the virions (Wang and Granados, 1997). The replicative cycle begins when ODVs infect the midgut columnar epithelial cells. ODVs possess a set of specific envelope-associated proteins, called per os infectivity factors (pif), which mediate virion-specific binding to receptors located at the membrane of midgut epithelial cells (Horton and Burand, 1993; Kikhno et al., 2002). To date, six proteins have been identified as members of this family, P74 (PIF-0), PIF-1, PIF-2, PIF-3, PIF-4, and PIF5 (ODV-E56; Faulkner et al., 1997; Kikhno et al., 2002; Pijlman et al., 2003; Ohkawa et al., 2005; Fang et al., 2009a; Harrison et al., 2010; Sparks et al., 2011). P74, PIF-1, and PIF-2 were shown to co-localize at the ODV envelope (Faulkner et al., 1997; Kikhno et al., 2002; Fang et al., 2006, 2009a; Harrison et al., 2010) and, together with PIF-3, constitute the core PIF complex that mediates viral entry. Afterward, viral entry occurs via a non-endocytic pathway through membrane fusion of the virion envelope with microvilli of epithelial cells, accompanied by the release of nucleocapsids into the cytoplasm. Nucleocapsids then migrate to the nucleus in a process that involves actin polymerization (Ohkawa et al., 2010).

Once having reached the nucleus, the host cell RNA polymerase-dependent transcription of viral immediate-early/early genes initiates $(0-6 \mathrm{~h}$ post-infection, hpi). This set of genes encodes mainly for transactivators essential for both subsequent viral gene expression and subversion of host cell activity (Passarelli and Miller, 1993). The transition from early to late phase is marked by the onset of viral DNA replication (6-18 hpi) and the activity of a virus-encoded RNA polymerase (Grula et al., 1981). Viral DNA replication occurs together with the expression of viral components necessary for the assembly of new nucleocapsids. The newly assembled nucleocapsids are transported from the nucleus to the plasma membrane for budding through GP64-enriched areas, thus originating the so called budded viruses (BVs; Passarelli, 2012). BVs are non-occluded virions surrounded by a plasma membranederived envelope containing GP64 as a major structural protein
(Washburn et al., 2003). BVs are required for secondary infection: once released, they are transported throughout the hemolymph to infect new cells, a process which, in contrast to what is described for ODVs, is undertaken by GP64 via clathrin-mediated endocytosis (Blissard and Wenz, 1992; Long et al., 2006). In this regard, BVs are the virus form responsible for viral dissemination throughout the host, culminating in a systemic infection. A secondary infection cycle begins with the entrance of BVs into another cell of the insect. After entering the cell, the infection process is similar to what happens in a primary infection, with the nucleocapsids traveling to the nucleus for DNA replication and subsequent viral protein expression. The very late phase of infection (18 hpi) initiates with the expression of proteins that constitute the crystalline matrix of the ODVs, namely polyhedrin. After nucleocapsid assembly, they are enveloped by the polyhedrin matrix to constitute the ODVs. The secondary cycle ends with the extensive infection of larvae tissues and cell lysis, culminating in insect larvae death, and dissemination of ODVs to the environment, where they can remain viable for several years until being ingested by other larvae (Volkman, 1997). Summarizing, BVs and ODVs are genetically identical but differ in their envelope compositions and tissue tropisms, and are produced at different times during infection.

The in vitro life cycle of baculovirus is similar to what happens in vivo, with a major difference that cultured cells need to be directly infected with the BVs. Since ODVs are forms resistant to environmental factors, there is no need of an occlusion matrix for in vitro virus survival. In fact, polyhedrin can be viewed as non-essential for baculovirus in vitro cell culture. Given that, recombinant baculoviruses are constructed by replacing the polyhedrin gene (polh) by a gene of interest under the control of the very late polh promoter (Merrington et al., 1997). Besides the strong activity of polh promoter, that allows high productivities of the recombinant protein, it is only expressed in the very late stage of the infection cycle.

\section{BACULOVIRUS INFECTION: IMPACT ON THE HOST CELL}

In the different phases of infection, baculoviruses induce profound changes on host cell properties. For that aim, several virus-encoded proteins interact with host cell factors, altering cellular structures and normal functions, and taking control of cellular gene expression machinery for their own profit (Table 1). As a result of such alterations several effects arise: cellular cytoskeleton rearrangement, cell cycle arrest and cytomegaly, apoptosis inhibition, metabolism subversion, and global shut-off of host protein synthesis. Current knowledge on the biology of the proteins involved in the regulation of each of these specific responses are reviewed and detailed below.

\section{VIRUS ENTRY, INTRACELLULAR TRANSPORT, AND EGRESS OF VIRIONS}

Viruses exploit cellular structures in order to be actively transported in the cells. Cytoskeleton proteins have been identified as important factors for viral replication and/or transcription (Fowler, 1990; De et al., 1991). In fact, virus entry, transport, and intracellular localization have been correlated with the reorganization of cytoskeleton proteins (Strauss, 1996; Cudmore et al., 1997). 
Table 1 | Baculovirus genes affecting host function.

\begin{tabular}{|c|c|c|c|c|}
\hline & $\begin{array}{l}\text { Baculovirus } \\
\text { protein/factors }\end{array}$ & Host counterparts & Function & Reference \\
\hline \multirow{4}{*}{$\begin{array}{l}\text { Cellular } \\
\text { adhesion/ } \\
\text { entry }\end{array}$} & $\begin{array}{l}\text { ODV: pifs (P74, PIF-1, } \\
\text { and PIF-2) }\end{array}$ & $\begin{array}{l}\text { Receptors on midgut } \\
\text { epithelial cells }\end{array}$ & Viral entry through membrane fusion & $\begin{array}{l}\text { Faulkner etal. (1997), Kikhno etal. } \\
\text { (2002), Fang etal. (2006, 2009a), }\end{array}$ \\
\hline & & & & Harrison et al. (2010) \\
\hline & BV: GP-64 & Receptors on cells & Viral entry by clathrin-mediated endocytosis & Blissard and Wenz (1992), \\
\hline & & & & Long et al. (2006) \\
\hline \multirow{13}{*}{$\begin{array}{l}\text { Cytoskeleton } \\
\text { remodeling }\end{array}$} & VP39, P78, VP80 & F-actin & $\begin{array}{l}\text { Actin cables formation for nucleocapsids } \\
\text { transport across the cytoplasm }\end{array}$ & $\begin{array}{l}\text { Xu etal. (2007), Ohkawa et al. } \\
\text { (2010), Marek et al. (2012) }\end{array}$ \\
\hline & Arif-1 & F-actin & Actin cables accumulation at cell borders & Roncarati and Knebel-Mörsdorf \\
\hline & & & & (1997), Dreschers etal. (2001) \\
\hline & le-1, PE38, HE65, & G-actin & Drive G-actin accumulation into the nucleus & Ohkawa etal. (2002) \\
\hline & Ac004, Ac102, Ac152 & & & \\
\hline & P78/83-C42 & G-actin & Arp2/3-mediated nuclear actin & Braunagel etal. (2001), Wang etal. \\
\hline & & & polymerization & (2008), Li etal. (2010) \\
\hline & P10 & $?$ & Nuclear integrity & Carpentier et al. (2008) \\
\hline & EXONO & $\beta$-Tubulin & Nucleocapsids engagement to & Fang et al. (2007, 2009a) \\
\hline & & & microtubular network and further egress & \\
\hline & Ac93 & $?$ & Intranuclear microvesicles formation for & Yuan et al. (2011) \\
\hline & & & virions maturation and egress & \\
\hline & $\mathrm{Bm} 61$ & $?$ & Egress & Shen and Chen (2012) \\
\hline \multirow{3}{*}{ Cell cycle arrest } & $\mathrm{EC} 27$ & Cdc2 & Cell cycle arrest at G2/M & Belyavskyi et al. (1998) \\
\hline & $\mathrm{EC} 27$ & Cdk6 & Override cellular checkpoints to allow viral & Belyavskyi et al. (1998) \\
\hline & & & DNA replication & \\
\hline \multirow{13}{*}{$\begin{array}{l}\text { Cellular stress } \\
\text { response }\end{array}$} & Lefs & ATM and/or ATR & $\begin{array}{l}\text { Viral DNA replication, shut off of host } \\
\text { protein synthesis }\end{array}$ & Kimberly et al. (2009) \\
\hline & PK1?; others & PI3K-Akt/MAPK- & Viral DNA replication/late gene expression & Reilly and Guarino (1994), Katsuma \\
\hline & & ERK-JNK & and progeny production & etal. (2007), Xiao etal. (2009) \\
\hline & & members & & \\
\hline & P35 & Effector caspases & Blockage of the apoptotic pathway & Clem etal. (1991), Kamita and \\
\hline & & & & Majima (1993), Bump etal. (1995), \\
\hline & & & & Bertin etal. (1996), Xu etal. (2001) \\
\hline & P49 & Initiator and effector & Blockage of the apoptotic pathway & Du etal. (1999), Pei etal. (2002), \\
\hline & & caspases & & Zoog etal. (2002), Guy and Friesen \\
\hline & & & & (2008) \\
\hline & IAPS & $?$ & Inhibition of apoptosis, activation of & Manji etal. (1997), Salvesen and \\
\hline & & & ubiquitination pathway & Duckett (2002) \\
\hline & $?$ & HSP/HSC70 & $\begin{array}{l}\text { Viral DNA replication, virions assembly and } \\
\text { maturation }\end{array}$ & Lyupina etal. $(2010,2011)$ \\
\hline Metabolism & $?$ & $?$ & $\begin{array}{l}\text { Boost in catabolic pathways to fuel } \\
\text { infection }\end{array}$ & $\begin{array}{l}\text { Iwanaga etal. (2007), Bernal etal. } \\
(2009,2010)\end{array}$ \\
\hline
\end{tabular}


The extent of cytoskeleton reorganization depends on the type of virus, suggesting that a myriad of strategies have co-evolved as a result of the specific interactions established between the virus and its host. Herpesvirus exploits actin and actin-associated myosin motors for viral entry, intranuclear transport of nucleocapsids, and virion egress (Roberts and Baines, 2011). Measles virus induces actin remodeling and microtubule formation upon cell entry, facilitating virus transport into perinuclear spaces, where viral replication occurs, and budding of the newly formed virions (Avota et al., 2011). HIV-1 remodels host cell cytoskeleton in a complex biphasic mode, promoting both inhibition of actin polymerization with looseness of cytoskeleton rigidity in order to favor virus entry, followed by actin remodeling and microtubule network rearrangement for viral cores delivery into the cytoplasm (Stolp and Fackler, 2011).

The impact of baculovirus infection on host cell cytoskeleton has been studied in detail. Baculoviruses encode several proteins that act in an organized and orchestrated way to remodel the cellular actin network throughout their life cycle (Figure 1).
Such cytoskeleton rearrangements are of crucial importance for baculovirus infection and proper assembly of newly synthesized virions. In fact, filamentous actin (F-actin) has been shown to be required for viral progeny production of lepidopteran nucleopolyhedroviruses such as AcMNPV, Spodoptera frugiperda MNPV (SfMNPV), Bombyx mori NPV (BmNPV), Orgyia pseudotsugata MNPV (OpMNPV), Lymantria dispar MNPV (LdMNPV), Anticarsia gemmatalis MNPV (AgMNPV), and Helicoverpa zea SNPV (HzSNPV; Kasman and Volkman, 2000).

During AcMNPV infection, three major actin cytoskeleton rearrangements occur. First, upon cell entry, F-actin cables can be detected throughout the cytoplasm, often associated with viral nucleocapsids. The formation of these actin cables is independent of viral gene expression, and correlates with the release of nucleocapsids from the endosomes upon internalization of BVs. Fluorescence microscopy studies showed the association of the nucleocapsids with one end of these actin cables, which might indicate the putative role of such structures in the transport of the nucleocapsids to the nucleus (Charlton and Volkman, 1993).

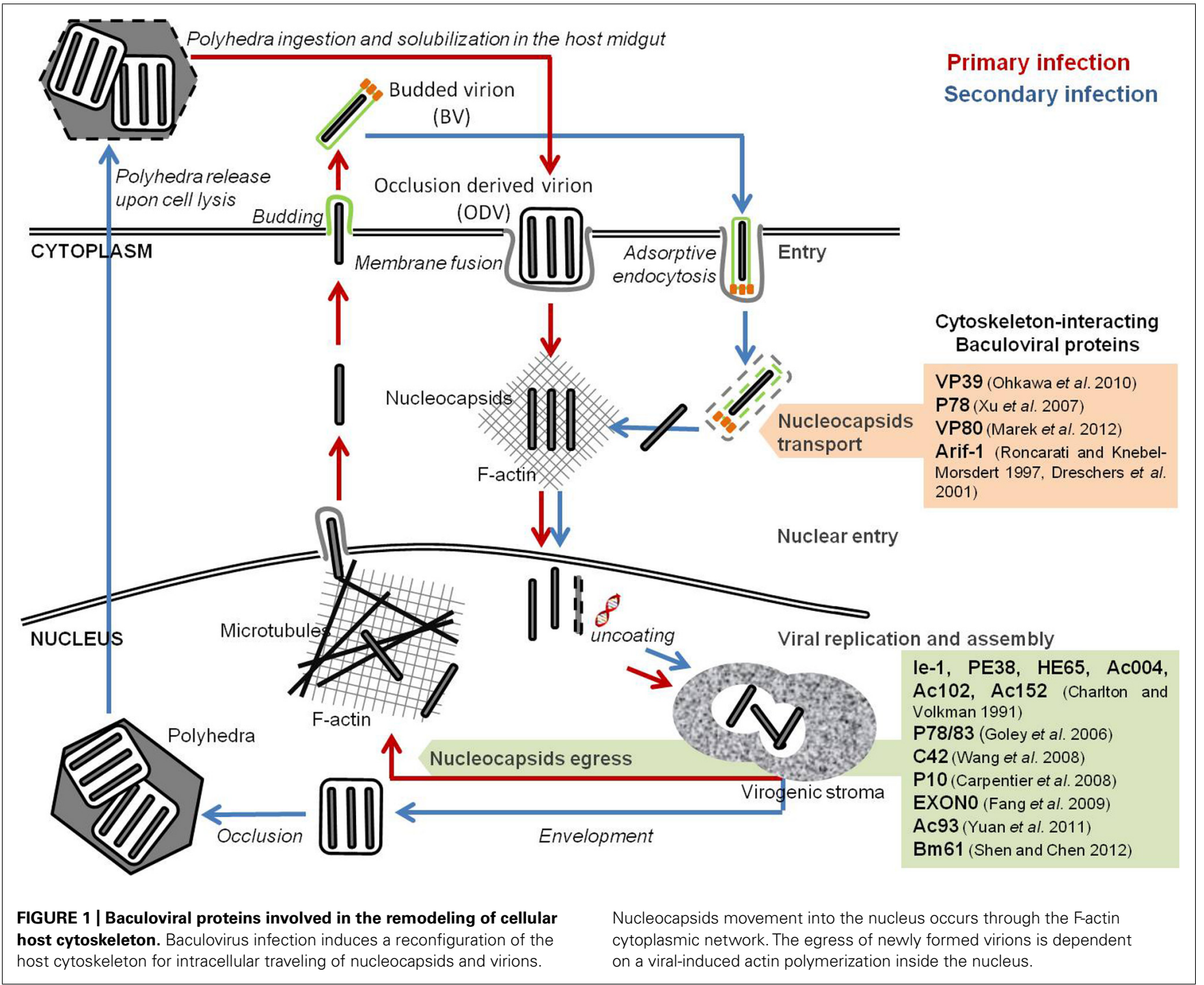


Lu et al. (2004) observed that Helicoverpa armigera NPV (HaNPV) VP39 nucleocapsid protein not only binds to actin, but also promotes its complexation to form actin cables structures, in vitro. In fact, it has been demonstrated that several AcMNPV nucleocapsid proteins (such as VP39, P78, and VP80) bind to actin directly (Xu et al., 2007; Ohkawa et al., 2010; Marek et al., 2012).

After early gene expression, a second alteration of the cytoskeleton occurs, with the formation of F-actin aggregates at the plasma membrane (Charlton and Volkman, 1991; Roncarati and KnebelMörsdorf, 1997). Concomitant with the intracellular release of nucleocapsids, actin cables localize at the cell surface and extend into the cytoplasm. At the onset of early gene expression, a rearrangement of the actin network is observed, during which actin cables become more prominent and accumulate at the cell borders (Roncarati and Knebel-Mörsdorf, 1997). This second change is mediated by the product of a single early viral gene, arif-1 (actin-rearrangement-inducing factor 1), a 47-kDa phosphoprotein that co-localizes with the F-actin aggregates (Dreschers et al., 2001). Expression of arif-1 alone leads to actin rearrangements comparable to the changes that happen at the late stage of early gene expression (Roncarati and Knebel-Mörsdorf, 1997). Immunofluorescence studies showed that, following AcMNPV infection, Arif- 1 co-localizes with F-actin at the plasma membrane until the onset of late gene expression, when Arif-1-induced actin polymerization is no longer detected. In fact, Arif- 1 analysis by SDS-PAGE showed that, between 12 and 48 hpi, multiple bands of higher molecular weight appeared, and that phosphatase treatment could reverse this observation. This suggests that Arif- 1 is inactivated by phosphorylation (Dreschers et al., 2001).

A third and more profound reconfiguration takes place during late gene expression, when F-actin appears within the nucleus, a feature almost exclusive to baculoviral infection and essential for nucleocapsids morphogenesis (Volkman, 1988; Ohkawa and Volkman, 1999; Kasman and Volkman, 2000). Monomeric globular actin (G-actin) starts to accumulate in the nucleus upon early gene expression. Six early viral gene products are implicated in this process: $i e-1$ and pe38, both transcriptional activators of several early, late, and very late genes (Blissard and Rohrmann, 1991; Lu and Carstens, 1993; Passarelli and Miller, 1993; Milks et al., 2003); he65, a RNA ligase involved in RNA replication, transcription, and modification (Rohrmann, 2011); and ac004, ac102, ac152, which products have not yet been characterized (Ohkawa et al., 2002; Gandhi et al., 2012). Nuclear actin is then polymerized into filaments (F-actin) by the products of late viral genes (Charlton and Volkman, 1991). Time-lapse microscopy studies showed that nuclear recruitment and actin polymerization is a precisely controlled dynamic process. During AcMNPV infection of TN-368 cells, G-actin accumulates in the nucleus between 10 and $20 \mathrm{hpi}$, and polymerization started $2 \mathrm{~h}$ after nuclear entry (Goley et al., 2006a). Such rapid turnover suggests the presence of a regulatory network that commands nuclear actin assembly during baculovirus infection. One such elemental regulator is the cellular Arp2/3 complex, which is activated to nucleate branched actin filaments by proteins called nucleation-promoting factors (NPFs; Welch and Mullins, 2002; Gandhi et al., 2012). In fact, several nucleopolyhedroviruses encode a capsid-associated protein, called p78/83 in AcMNPV, that contains conserved domains of the Wiskott-Aldrich syndrome protein (WASP) family of NPFs (Machesky etal., 2001). However, both the p78/83 protein and the Arp2/3 complex self-localize in the cytoplasm of uninfected cells (Goley et al., 2006a), which points out that another viral protein must participate to recruit both factors to the nucleus. It has been suggested that AcMNPV encoded nucleocapsid protein, C42, a product of a late gene highly conserved among members of the Baculoviridae family, is responsible for nuclear recruitment of $\mathrm{p} 78 / 83$ and Arp2/3. This protein is present in both BVs and ODVs, possesses a putative nuclear localization signal (NLS) motif and binds to the p78/83 protein in a nucleocapsidindependent manner (Braunagel et al., 2001; Wang et al., 2008; Li et al., 2010). Taken together, the above mentioned cellular and viral factors are believed to act in an orchestrated way to promote actin transport into the nucleus and further polymerization. This step is of paramount importance for proper virion assembly and infectivity, since in the presence of cytochalasin D or latrunculin A, two drugs that interfere with F-actin function, viral progeny production is inhibited, a phenotype observed in several divergent nucleopolyhedroviruses (Kasman and Volkman, 2000).

Also in the late phase of infection, the P10 late viral protein starts to aggregate, forming a thick tubular network surrounding the nucleus that projects into the cytoplasm (Carpentier et al., 2008). During infection the nucleus swells as a result of the accumulation of viral proteins and virions. This $\mathrm{P} 10$-associated cage may stabilize the nucleus, preventing its disruption before the ODV s have completely matured and, stabilizing the architecture of cells long enough for the virus to complete its replication process (Carpentier et al., 2008).

Once the virions progeny have properly matured, they need to be transported from the nucleus toward peripheral budding sites. One component that is involved in this egress pathway is EXON0, a conserved structural protein of BV and ODV nucleocapsids found in all lepidopteran alpha-baculoviruses (Fang et al., 2007). Co-immunoprecipitation and confocal immunofluorescence microscopy studies showed that EXON0 interacts with $\beta$-tubulin, enabling the "engagement" of BV nucleocapsids with the microtubular network (Fang et al., 2009b). This assists the transport of nucleocapsids in the nucleus from the virogenic stroma to the nuclear envelope and their migration to the plasma membrane. Recently, Yuan et al. (2011) identified a core gene, ac93, as an important player in AcMNPV nucleocapsids egress from the nucleus. Mutagenesis assays showed that ac 93 is required for intranuclear microvesicle formation and egress, thus affecting BVs production and ODVs envelopment. Moreover, immunofluorescence microscopy revealed the presence of Ac93 moving toward the cytoplasmic membrane and in the ring zone of the nucleus, late in infection. In fact, this protein was detected in association with the nucleocapsid fraction of both BV and ODV, and the envelope fraction of $\mathrm{BV}$, which further supports its involvement in virion maturation and egress (Yuan et al., 2011). Shen and Chen (2012) identified another core gene, $B m 61$, as a participant in the egress of BVs during $B m \mathrm{NPV}$ infection. Deletion of Bm61 blocked the production of BVs, although DNA replication still occurred. In fact, electron microscopy analysis showed that, despite nucleocapsid assembly still occurred, they remained trapped in the nucleus 
by impairment of the egress route to the cytoplasm, leading to loss of BVs production. Furthermore, fluorescence microscopy showed the presence of Bm61 at the intranuclear ring zone and nuclear membrane, which illustrates its role in the transport of nucleocapsids to the cytoplasm (Shen and Chen, 2012).

Summarizing, actin and tubulin networks have important roles throughout baculovirus infection. The virus undertakes a successful and dynamic manipulation of cellular cytoskeleton, and these effects span all the infection process from virus entrance and transport to the nucleus, to nucleocapsid formation and egress, which is at the core of successful infection and replication.

\section{CELL CYCLE ARREST}

The cell cycle involves a series of events that take place in a cell leading to its division and duplication. A complete cellular cycle comprises four sequential stages: G1, S, G2, and mitosis. DNA replication and cell division are highly regulated processes that occur at $\mathrm{S}$ and $\mathrm{M}$ phases, respectively. G1 and G2 are gap phases where the cell prepares itself for the next stage. Progression from one stage to the following is controlled by cyclins and cyclindependent kinases $(\mathrm{Cdk})$, which are in turn regulated by a plethora of pathways in response to external stimuli, as well as to the internal conditions of the cell (Morgan, 1995).

A common feature of many viral infections is the subversion of the host cellular cycle to create an intracellular environment suitable for maximized viral DNA replication (Ben-Israel and Kleinberger, 2002; Spink and Fluck, 2003; Chen and Qiu, 2010; Sakai etal., 2011; Li etal., 2012). Very diverse strategies have been developed by viruses, from the stimulation of cell cycle progression in quiescent cells, to blockade of cell cycle progression in proliferating ones (Op De Beeck and Caillet-Fauquet, 1997; Davy and Doorbar, 2007). For instance, HIV Vpr-mediated arrest at G2/M can benefit the early infection stages by increasing the number of integrated proviruses (Groschel and Bushman, 2005). In turn, adenovirus and SV40 polyomavirus infection induces the cell to remain in a pseudo-S phase state, during which normal cellular DNA replication is complete, but the cell still remains competent for viral DNA replication (Lehman et al., 1994, 2000; Ben-Israel and Kleinberger, 2002).

Baculovirus infection of insect cells causes cell cycle arrest in the G2/M phase (Figure 2). Braunagel et al. (1998) showed that when Sf 9 cells were infected with AcMNPV, approximately $84 \%$ of the total cellular population was arrested in G2/M phase by $18-24 \mathrm{hpi}$. Concomitantly, high levels of Cdc2-associated histone $\mathrm{H} 1$ kinase and cyclin $\mathrm{B}$ were detected, with the kinase activity remaining detectable through the course of infection. Moreover, this arrest was proven to be necessary for optimal ODVs maturation and assembly since arresting $S f 9$ cells at G1/S boundary by chemical treatment led to abnormal intranuclear microvesicle formation and, consequently, impairment of ODV maturation (Braunagel et al., 1998). During regular cell cycle, cyclin B associates with Cdc2 and this complex is responsible for the progression from G2 to M. The complex accumulates in the nucleus, and once activated by Cdc25, induces a cascade of nuclear architecture rearrangements culminating with the breakdown of nuclear lamina with increased envelope fluidity, therefore committing cells to start dividing. Afterward, cellular cyclin B is degraded and the cell progresses to anaphase (Draetta and Beach, 1989; Nurse, 1994). These findings

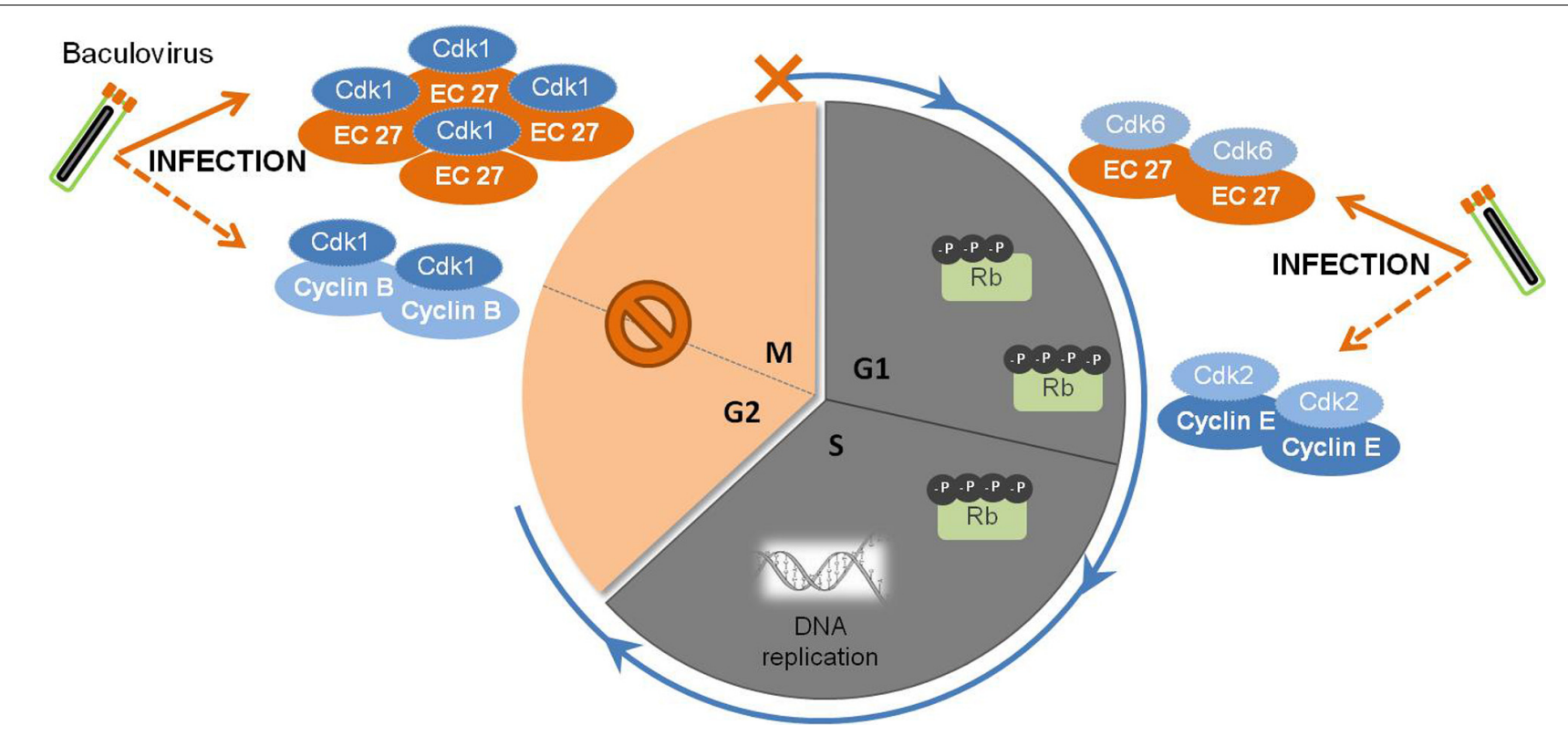

FIGURE 2 | Baculovirus subversion of host cellular cycle. Early in infection, the baculovirus causes the augmentation of cellular levels of Cdk1-cyclin B complexes, which are responsible for the regulation of the transition of $\mathrm{G} 2$ to $M$ phase. Later on, a viral homolog of host cyclin $B, E C 27$, starts to be expressed and accumulates in the cell. The complex Cdk1-EC27 blocks the cell cycle, and the cells remain arrested In the G2/M phase during the course of infection. Also, EC27 can act in a cyclin D-dependent manner, forming the complex Cdk6-EC27. As a result, the retinoblastoma protein $(\mathrm{Rb})$ becomes phosphorylated, together with the activation of the complex Cdk2-cyclin E. Such phenomena will trigger the components needed for DNA replication, ensuring an environment favorable for viral DNA synthesis and replication. 
suggest that early in infection, the cyclin B-Cdc2 complex may be used to regulate the transition from G2 to M phase. However, since only the kinase activity is detectable throughout infection, the prolonged cell cycle arrest during baculovirus infection may be due to a protein(s) encoded by AcMNPV. In fact, AcMNPV was shown to encode a human cyclin homolog protein, the EC27 protein. This protein was described as having a multifunctional operating mode, being able to act in a cyclin B and cyclin D-dependent manner (Belyavskyi et al., 1998). By encoding a cyclin B-like protein, baculoviruses are able to arrest the cellular cycle at G2/M phase maintaining the nuclear architecture at its best for virions progeny assembly and maturation. Actually, the cellular phenotype alterations manifested throughout baculoviral infection, such as enlarged nucleus, increased envelope fluidity, and induction of microvesicles and membranes in the nucleoplasm (Summers and Arnott, 1969; Braunagel et al., 1998), supports EC27 cyclin B-like functions. However, this baculovirus encoded cyclin B does not lead to the breakdown of the nucleus, which remains intact in infected cells, possibly indicating that there are differences with the host protein.

Baculovirus infection of insect cells induces the shut-off of global host protein synthesis by 18 hpi (Carstens et al., 1979; Du and Thiem, 1997), concomitant with the cell cycle arrest at G2/M (Braunagel et al., 1998; Ikeda and Kobayashi, 1999). In fact, beyond this time frame, cellular DNA replication is no longer detected, in opposition to viral DNA replication and gene expression. The presence of an active Cdk6-EC27 complex with cyclin D-like activity can explain this behavior. In non-infected cells, cyclin D association with Cdk6 promotes G1 to S phase transition by phosphorylation of $\mathrm{pRb}$ (retinoblastoma protein), a key regulator of the cell cycle (Dowdy et al., 1993; Ewen et al., 1993). Moreover, Cdk-cyclin complexes can "titrate" Cdk inhibitors resulting in activation of the Cdk2-cyclin E complex (Polyak et al., 1994) which then affects components of the pre-initiation complexes to trigger DNA replication (Stillman, 1996). Such observations clearly show that baculovirus encodes specific mechanisms to override cellular checkpoints, which benefits both viral DNA replication and virion assembly and maturation.

\section{CELLULAR STRESS RESPONSE}

Infection is sensed by cells as a stressful situation. Accordingly, viruses trigger diverse cellular responses, including the activation of apoptosis, DNA damage, and heat shock responses (HSR), aimed at fighting the infection by preventing virus replication and dissemination. Consequently, viruses have evolved several strategies in order to circumvent these defense responses. In this section, specific features of baculovirus-host interactions during cellular responses to infection will be discussed. Although these responses are coordinated, for the sake of simplicity, they will be treated separately.

\section{Induction of DNA damage response and pro-survival pathways}

Several viruses have evolved mechanisms to manipulate the DNA damage response triggered upon viral infection (Chaurushiya and Weitzman, 2010). The cellular response to the presence of damaged DNA is dependent on the activation of two members of the phosphatidylinositol 3-kinase (PI3K) superfamily, the ataxia telangiectasia mutated (ATM) and rad3-related (ATR) proteins (Seviour and Lin, 2010). These systems respond to doublestrand breaks in DNA, and single-strand breaks along with stalled replication forks, respectively (Huang et al., 2011). As discussed later on, the downstream effects of the activation of this system include the phosphorylation of numerous effector proteins which function in cell cycle checkpoints, DNA repair, and stimulation of apoptosis. Interestingly, one important downstream substrate of ATM and ATR is P53, which is actively inhibited by many DNA viruses to avoid the inhibition of cell cycle progression and stimulation of apoptosis in response to DNA damage (Huang et al., 2011).

Several mammalian viruses induce a cellular DNA damage response during replication which, in some cases, is required for optimal virus replication. For instance, SV40 efficient DNA replication and virions assembly is dependent on the activation of ATM (Zhao et al., 2008). HSV and HIV-1 also activate ATM, and that ATM signaling is important for viral replication (Lau et al., 2005; Lilley et al., 2005). This is also the case for baculoviruses. In fact, induced apoptosis and shut-off of host protein synthesis are the result of the activation of cellular DNA damage response, and this activation is triggered by viral DNA replication (Clem and Miller, 1994; LaCount and Friesen, 1997; Kimberly et al., 2009). RNA silencing assays directed to genes essential to AcMNPV replication identified the replicative late expression factors (lef) as the source of the critical apoptotic signal in infected cells, which also contribute to the inhibition of host cell protein synthesis (Kimberly et al., 2009). Moreover, the addition of ATM and ATR inhibitors to $S f 9$ cultures infected with AcMNPV decreased viral DNA replication and late gene expression (Huang et al., 2011). In this sense, baculovirus control of the cellular response against infection can be viewed as an equilibrium in which the virus takes advantage of the activation of the DNA damage response for DNA replication, shut-off of host protein synthesis to have the machinery available for viral protein expression, together with inhibition of apoptosis by expressing anti-apoptotic factors (Figure 3).

Concomitant with the induction of the stress response, viral infection also activates and modulates pro-survival cellular pathways (Cooray, 2004; Ji and Liu, 2008; Furler and Uittenbogaart, 2010; Qin et al., 2011). The mitogen-activated protein kinases (MAPKs), such as extracellular signal-regulated molecule kinase (ERK) and c-Jun $\mathrm{NH}_{2}$-terminal kinase (JNK), are involved in the regulation of a plethora of cellular processes, including cell division and control of transcription (Johnson and Lapadat, 2002). The PI3K-Akt pathway controls cell survival and apoptosis, proliferation, migration, and regulates metabolism (Willems et al., 2012). In light of this knowledge, it is not surprising that viruses exploit such cellular pathways to set-up an intracellular environment suitable for efficient replication and progeny production. In fact, hepatitis-B, Epstein-Barr, and vaccinia virus are known to subvert MAPK pathways, a behavior that is behind successful infections (de Magalhães et al., 2001; Zheng et al., 2003; Gao et al., 2004). During influenza A virus infection, the PI3K-Akt signaling pathway is activated, and inhibition of PI3K results in reduced viral RNA synthesis, protein expression, and viral yield (Shin et al., 2007). Also, human cytomegalovirus (Johnson et al., 


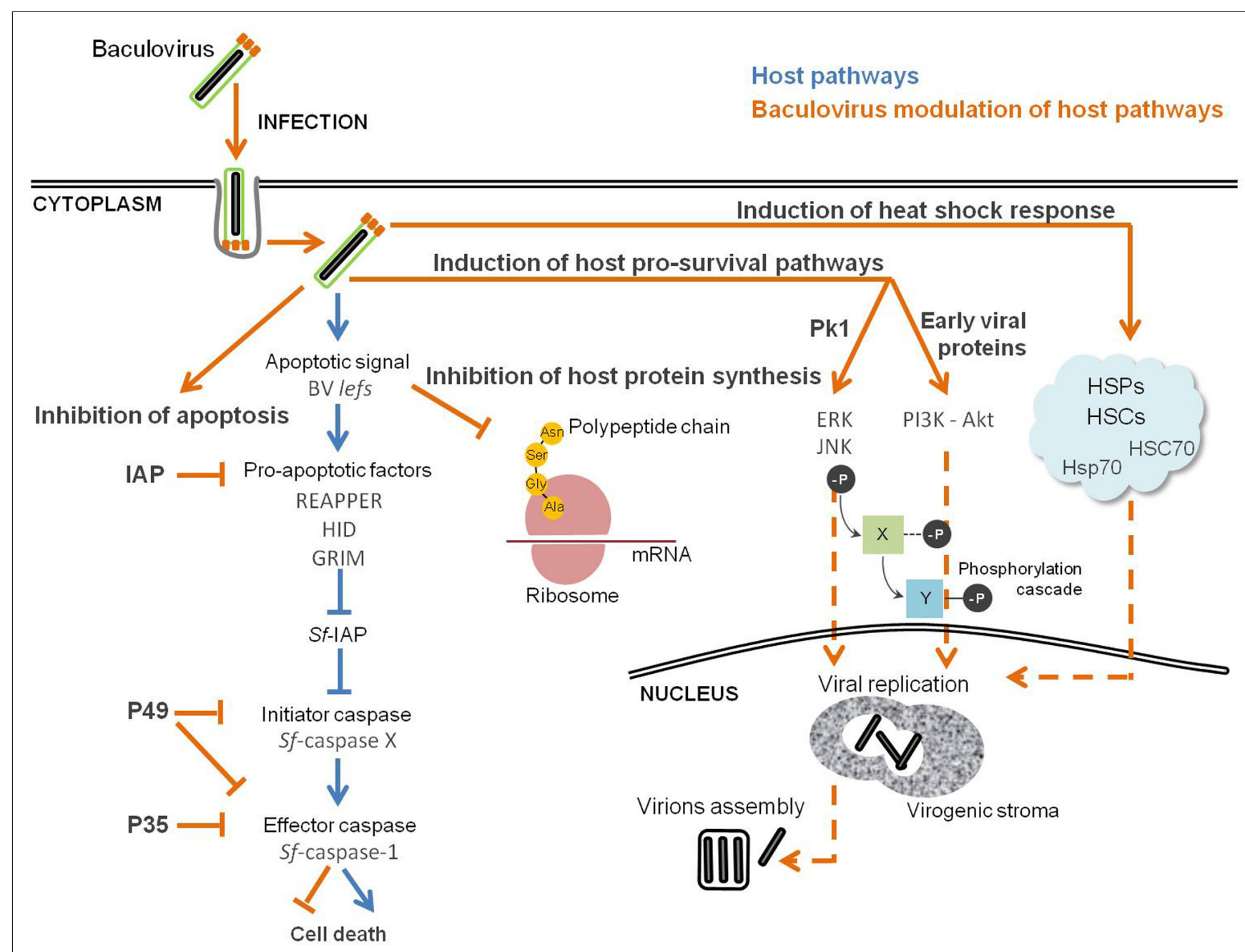

FIGURE 3 | Baculovirus manipulation of host cellular stress response. Successful infection is the result of a compromise between host defense response and inhibition of apoptosis, which creates the perfect environment for the replication of the virus. Pathways in "orange" are viral and in "blue" are from the host.

2001) and coxsackievirus B3 (Luo et al., 2002; Esfandiarei et al., 2004) depend on the activity of PI3K-Akt and/or MAPK-ERK for efficient replication. It has been previously shown that baculovirus efficient infection is dependent on the activation of both MAPK and PI3K signaling (Figure 3). Successful infection of $B m \mathrm{NPV}$ is dependent on the activation of ERK and JNK signaling pathways (Katsuma et al., 2007). Western blot assays revealed that ERK and JNK were activated at the late stage of $B m \mathrm{NPV}$ infection, and inhibition of both kinases after 12 hpi significantly reduced occlusion body formation and BVs production (Katsuma et al., 2007). Also, late and very late gene expression was impaired, suggesting an important role for ERK and JNK in regulating the $B m \mathrm{NPV}$ gene expression program. During AcMNPV infection of $S f 9$ cells the levels of phosphorylated Akt became elevated, and inhibition of PI3K-Akt activation significantly reduced viral yield, BV production, and occlusion body formation (Xiao et al., 2009). The activation of the PI3K-Akt signaling pathway occurs at an early stage of AcMNPV infection, and is of major importance for viral DNA replication. Inhibition of PI3K at 12 hpi not only reduces the level of viral DNA synthesis, but also delays late and very late gene expression. This result is not surprising, since the transition from early to late phase is marked by the onset of viral DNA replication, which in turn occurs together with the expression of very late genes coding for viral structural components necessary for the assembly of new virions (Grula et al., 1981). Taken together, these data suggest that the products of early genes prepare the host cell for viral multiplication, shown here by the activation of PI3K-Akt pathway, ensuring an environment suitable for efficient infection. However, it is not clear which viral proteins are involved in the activation of these signaling pathways. Baculoviral PK1 serine/threonine protein kinase is expressed along with AcMNPV infection and it is essential for $B m \mathrm{NPV}$ replication in $B m \mathrm{~N}$ cells (Reilly and Guarino, 1994; Katsuma et al., 2007). These data suggest that phosphorylation of host and/or viral proteins by PK1 is needed for virus replication, indicating $\mathrm{PK} 1$ as a viral candidate for the activation of ERK and JNK kinases. Further studies concerning the identification of the viral counterpart(s) responsible(s) for the activation of these signaling pathways are compulsory. 


\section{Inhibition of apoptosis}

As mentioned before, one of the pathways targeted by the DNA damage response is apoptosis, or programmed cell death, which is a highly regulated process widespread among multicellular organisms. It is characterized by apoptotic body formation, cell shrinkage, membrane blebbing, chromatin condensation and DNA fragmentation, culminating in cellular death (Kerr et al., 1972). Such mechanism is evolutionarily conserved, with the convergence of the apoptotic stimuli to a central pathway that encloses a family of aspartate-specific cysteinyl proteases, i.e., caspases, the main activators and executioners of the apoptotic response. The caspases family is divided in two classes, initiator caspases and effector caspases, which are activated in a sequential manner by auto cleavage in response to apoptotic signaling (Ma and Chang, 2011).

In order to counteract this defense, several viruses have developed mechanisms to block the premature apoptosis of infected cells. These strategies range from mimicking specific cellular regulators, which is the case of the Epstein-Barr virus, African swine fever virus, and herpesvirus, that encode viral homologs for the cellular anti-apoptotic protein Bcl-2, or expressing viralspecific proteins, like the cowpox virus $\mathrm{CrmA}$ anti-apoptotic factor (Koyama et al., 2000; Aubert and Blaho, 2001).

Although currently this is observed as a general key strategy, the stimulation of apoptosis by infection was first demonstrated in the baculovirus system (Figure 3). Clem et al. (1991) found that baculovirus replication in insect cells triggers apoptosis, and a specific viral gene product, the AcMNPV $p 35$, was identified as being responsible for blocking the apoptotic response. In fact, it was later shown that $\mathrm{P} 35$ protein is a direct substrate inhibitor of caspases and acts in a stoichiometric manner as a suicide inhibitor (Bump et al., 1995). Caspase-mediated cleavage at the aspartate residue Asp87 within the P35 reactive-site loop leads to the formation of a stable complex covalently bound to the target caspase, subsequently inhibiting apoptosis (Bertin etal., 1996; Xu etal., 2001). In addition to AcMNPV, other baculoviruses have been found to carry $p 35$ homologs, BmNPV and Spodoptera litoralis NPV (SlNPV). The BmNPV p35 gene has high nucleotide and amino acid sequence identity to the AcMNPV gene, and its presence is needed to inhibit $B m \mathrm{NPV}$ induced apoptosis in B. mori cells (Kamita and Majima, 1993). The SlNPV p49 gene encodes a protein with $49 \%$ amino acid identity with its AcMNPV homolog p35 (Du et al., 1999). Computer-assisted modeling and site-directed mutagenesis suggests that the structure of P49 resembles P35, including the presence of a prominent reactive loop that presents Asp94 for cleavage (Pei et al., 2002; Zoog et al., 2002). P49 has the ability to inhibit both initiator and effector caspases, whereas P35 can only inhibit effector caspases. P49 is a substrate inhibitor of the initiator caspase Sf-caspase-X, which is responsible for the proteolysis and activation of Sf-caspase- 1 and -2 (Zoog et al., 2002; Guy and Friesen, 2008). This indicates that P49 acts upstream of P35 by inhibiting initiator caspases responsible for the activation of effector caspases.

Another family of baculovirus anti-apoptotic genes is the iap (inhibitor of apoptosis) family. These genes are present in genomes from yeasts to humans, and are known to regulate apoptosis and several other cellular functions (Salvesen and Duckett, 2002;
Gyrd-Hansen and Meier, 2010). The first iap genes described in nature were discovered by complementation assays in Cydia pomonella granulovirus (Cp-iap) and Orgyia pseudotsugata nucleopolyhedrovirus (Op-iap; Crook etal., 1993; Birnbaum etal., 1994), in which the iap gene compensated for the lack of $p 35$ in the annihilator AcMNPV mutant. At least one iap gene is present in almost all the baculovirus genomes sequenced, whereas $p 35$ genes are present in only a small subset (Clem, 2005). Op-IAP was shown to function upstream of P35 in Sf21 cells, since its expression was sufficient to block effector Sf-caspase-1 processing, while P35 was not (Manji et al., 1997; Seshagiri and Miller, 1997). However, besides these two examples many of the iap genes tested so far do not seem to have the ability to inhibit apoptosis, or this ability is cell type-specific (Bideshi et al., 1999; Maguire et al., 2000). Moreover, given their ubiquitous distribution, maybe their anti-apoptotic activity is restricted to certain scenarios, or they may possess other functions in different viral processes, such as ubiquitin ligases, as shown for other cellular and viral IAPs (Yang et al., 2000; Imai et al., 2003; Green et al., 2004). Structurally, IAP proteins are metalloproteins with one to three copies of a zinc-binding motif, BIR (Baculovirus IAP Repeat), at the N-terminus, and another zinc-binding motif, RING, at the C-terminus (Hinds et al., 1999). BIR-containing motifs of several IAP proteins bind directly a myriad of pro-apoptotic proteins (Miller, 1999). In fact, BIR2 motif of Op-IAP interacts with Drosophila pro-apoptotic factors REAPPER, HID, and GRIM, and this binding inhibits apoptosis even during overexpression of such factors in Sf21 cells (Vucic et al., 1997, 1998a,b). The RING domain is also important, since its removal completely abolishes Op-IAP anti-apoptotic activity and strongly diminishes its ability to protect $S f 21$ cells during HID overexpression (Vucic et al., 1998a; Wright and Clem, 2002). RING motif-containing proteins are involved in many cellular functions, ranging from scaffolding of multi-protein complexes (Borden, 2000) to E3 ubiquitin ligase activity (Tyers and Willems, 1999). Actually, the Op-IAP RING domain has been shown to have E3 ubiquitin ligase activity, capable of promoting its own and HID ubiquitination, and this ability is of major importance for OP-IAP anti-apoptotic properties (Green et al., 2004). Ubiquitination is a post-translational modification that can have different effects on the targeted substrate, such as targeting to proteasome-dependent proteolysis or the modulation of protein function, structure, assembly, and localization (Deshaies and Joazeiro, 2009). The relevance of this activity for the in vivo anti-apoptotic function of Op-IAP is still unclear. Direct interaction and subsequent modulation of proapoptotic factors by IAP proteins is evident, and further studies are encouraged in order to disclose the peculiarities of such dynamic cross talk.

\section{Induction of the heat shock response}

A hallmark of universal cellular defense to various environmental and pharmacological stresses is the activation of the HSR (Gidalevitz et al., 2011). The induction of HSR leads to the rapid and robust expression of members of the chaperone family of heat shock proteins (HSPs) and respective cognates (HSCs), in order to protect the cell from proteotoxic stresses and to maintain protein homeostasis (Fujimoto and Nakai, 2010). 
HSP70s and HSP90s, members of the HSPs family, are involved in the replicative cycles of DNA and RNA viruses. Not only have they been identified in the regulation of viral gene expression via interaction with specific viral proteins, but they also participate in capsid assembly and disassembly (Mayer, 2005; Xiao et al., 2010; Nagy et al., 2011). Such observations demonstrate that viruses also exploit HSR as an infection strategy. A proteomic study by 2D-GE coupled with mass spectrometry showed that host HSC70 was associated with ODV of $B m \mathrm{NPV}$, suggesting a possible involvement of HSP during the assembly of baculoviral virions (Liu et al., 2008). Nobiron (2003) used a differential display approach to search for host mRNA transcripts that could be up-regulated during AcMNPV infection of $S f 9$ cell line. They found one transiently up-regulated transcript encoded by $h s c 70$, for which expression peaked at 6 hpi. Similarly, a microarray approach to analyze the global transcriptional profile of infected $B$. mori cells showed that the $h s c 70$ ortholog was up-regulated during infection, and this increase was detected only until 24 hpi (Sagisaka et al., 2010). A combined microarray assay complemented with qRT-PCR was applied for $S f 21$ transcriptome analysis during the infection with AcMNPV (Salem et al., 2011). Despite the fact that the majority of cellular genes were down-regulated during the course of infection, the expression of two members of the hsp70 family were augmented. Lyupina et al. (2010) monitored the induction of HSPs of the 70-kDa family (HSP/HSC70) in Sf9 cells after infection with AcMNPV by Western blot analysis. The authors reported that $A c \mathrm{MNPV}$ infection induces and stimulates several HSP70s, and that the infection process markedly potentiates HSR by boosting the HSP/HSC70s content (Figure 3). The use of chemical inhibitors of HSR decreased the rate of viral DNA synthesis, providing experimental evidence of the importance of such pathway for baculovirus replication. Moreover, HSP70s colocalize with ubiquitinylated proteins in speckles in the cytoplasm of AcMNPV-infected cells, forming aggresome-like structures that can contain proteins for digestion and/or sequestration during infection (Lyupina et al., 2011). In fact, the ubiquitin-proteasome system is required during $B m \mathrm{NPV}$ infection, since its inhibition resulted in reduced BV and ODV formation, together with the suppression of polyhedrin expression (Katsuma et al., 2011). Ubiquitin homologs are found in most lepidopteran baculovirus genomes (Katsuma et al., 2008). Although non-essential for viral replication, the baculovirus ubiquitin protein $(v-\mathrm{UBI})$ is involved in the formation of AcMNPV viral particles, since its loss resulted in a reduction of BV production (Reilly and Guarino, 1996). Additionally, biochemical experiments suggest a putative role for $v$-UBI in the blocking of the host degradative pathways of short-lived protein(s) during infection (Haas et al., 1996). Taken together, these data suggest a close collaboration of HSPs and ubiquitin-proteasome system during the baculovirus replicative cycle. Studies exploring the interactome profile between viral proteins and factors triggered upon stress induction are strongly encouraged, in order to identify the players and mechanisms responsible for balancing host damage and stress response.

\section{METABOLISM}

Viral infection claims an intensification of host cell biosynthetic activity in order to supply building blocks needed for the biogenesis of membrane lipids and for the synthesis of viral nucleic acids and proteins (Munger et al., 2006, 2010). In fact, viruses are considered as "metabolic engineers" (Maynard et al., 2010). In this regard, the success of infection is highly dependent on the metabolic state of the cells at the moment of infection, jointly with the viral manipulation of energy metabolism to fit such needs (Carinhas et al., 2010, 2011a). Despite many recent reports, the characterization of insect cell metabolic response to baculovirus infection is still at its infancy.

Baculovirus infection provokes an important metabolic burden on insect cells, causing an enhancement of the fluxes through the major catabolic pathways, namely glycolysis and tricarboxylic acid cycle (TCA; Bernal et al., 2009) as reflected in the changes in fluxes and enzyme activities after infection (Bernal et al., 2010; Figure 4). An increase in the oxygen uptake rate is also observed, which accounts for a higher rate of respiration upon infection (Kamen et al., 1996; Palomares et al., 2004; Bernal et al., 2009). Moreover, there is a drop in systems productivity when insect cells are infected with baculovirus at high cell densities, the so called "cell density effect." Bernal et al. (2009) succeeded in deciphering the metabolic basis of such phenomenon, during which Sf 9 cells undergo a progressive inhibition of central metabolism (Bernal et al., 2009). Since a successful viral infection strongly correlates with the energetic state of the cell, viral replication is impaired in high cell density cultures. Iwanaga et al. (2007) performed an exploratory analysis using subtractive hybridization in order to identify differentially expressed host genes following $B m \mathrm{NPV}$ infection. The authors paid special attention to the response of energy metabolism to infection, and reported the up-regulation of citrate synthase and ATP-dependent proteasome $26 S$ homologous genes. Citrate synthase is the first enzyme of the TCA cycle, which plays a central role in aerobic energy production and metabolic interconversions in mitochondria (Holloszy et al., 1970). On the other hand, the proteasome-ubiquitin pathway plays an important role during baculovirus infection as mentioned previously (Katsuma et al., 2011). Next-generation sequencing and gene enrichment analysis also showed that gene sets related to mitochondrial function were highly up-regulated during the course of $B m \mathrm{NPV}$ infection of Bm5 cells (Xue et al., 2012). A recent high-throughput analysis of baculovirus proteomic responses of Sf 9 cells to infection with AcMNPV identified two up-regulated metabolic enzymes, pyruvate dehydrogenase and aldehyde dehydrogenase (Carinhas et al., 2011b). Therefore, the up-regulation of such cellular proteins indicates that baculoviruses manipulate host energy metabolism to fuel its own replication and further envisages the importance of energy metabolism in supporting infection.

All these alterations described in central metabolism are linked to the host-virus interactions described in the previous sections. Baculovirus replication depends on the activation of PI3K-Akt signaling pathway (Xiao et al., 2009). One of the downstream targets of Akt is the adenosine $5^{\prime}$ monophosphate (AMP)-activated kinase (AMPK), a key sensor which regulates the metabolic status of cells (Cantó et al., 2009). In fact, it is activated by an increase in the AMP:ATP ratio (i.e., a low energy charge) and balances energy homeostasis by up-regulating catabolic processes while inhibits anabolism. A similar regulatory mechanism is activated 


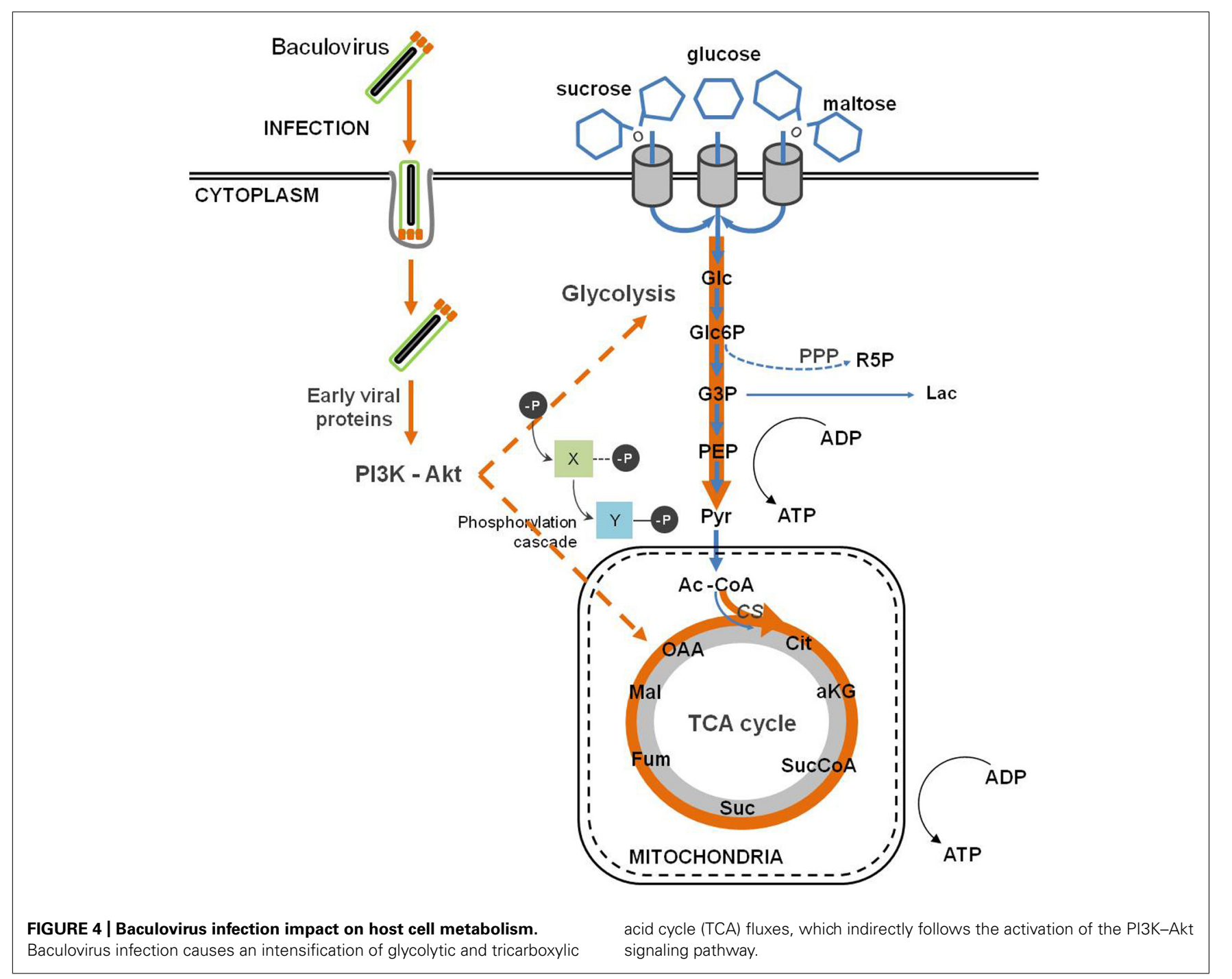

in other viruses (Terry et al., 2012). In addition, both AcMNPV and $B m$ NPV encode nucleotide diphosphate hydrolases belonging to the Nudix family. The corresponding genes are expressed early in infection and are essential for the replication of the virus (Ge et al., 2007; Chen et al., 2010). The essentiality of this activity is intriguing, although several metabolic regulatory roles have been proposed for nucleotides and related metabolites, which might contribute to the observed effects of infection (Tong and Denu, 2010).

\section{PROTEOMIC ANALYSIS OF BACULOVIRUS-HOST CELL INTERACTIONS}

As seen along the previous sections, viral infection induces profound alterations on the physiology of the host cells, and the latter respond to such changes by translating a complex network of protein-protein interactions and biochemical signaling events into functional responses. Systems level knowledge about the host effectors involved in the response to virus infection and the functions induced by viruses is crucial to understand the molecular basis of viral pathogenesis at a whole cell/organism level.
In addition to their well proven biotechnological and biomedical potentials, the study of the molecular biology of baculovirus infection has also offered meaningful insights into conserved viral mechanisms of manipulation and subversion of the host cell (Clem, 2001; Goley et al., 2006b).

Despite the advances in the so-called omic technologies, their application to the baculovirus-host system has been held back by the lack of sequenced host genomes, and the scarcity of curated databases. While complete genome sequences for more than 53 baculovirus are available (van Oers, 2011), currently, the only fully sequenced insect host is B. mori (Xia et al., 2004). Global gene expression profiles of $S$. frugiperda and B. mori derived cell lines have been recorded at various time-points, following baculovirus infection (Nobiron, 2003; Iwanaga et al., 2007; Sagisaka et al., 2010; Salem et al., 2011). Also, the temporal gene expression programs of the viral genes of several members of the Baculoviridae family ( $A c \mathrm{MNPV}, \mathrm{TnSNPV}, \mathrm{Bm} \mathrm{NPV}$ ) have been elucidated during their respective infection cycles (Yamagishi et al., 2003; Iwanaga et al., 2004, 2007; van Munster et al., 2006). Even scarcer are large scale proteomic studies. Popham et al. (2010) performed a proteomic 
analysis based on 2D-GE-MS/MS to examine the protein expression of permissive and non-permissive insect host cells ( $H$. zea and Heliothis virescens derived cell lines, respectively) for AcMNPV. The authors identified 18 differentially expressed proteins after $24 \mathrm{hpi}$ in the permissive cell line, among which there were members of signal transduction pathways, protein function and homeostasis, and cell survival (Popham et al., 2010). Recently, Carinhas et al. (2011b) applied a SILAC approach for quantitative proteomics of $S f 9$ cells during growth and early baculovirus infection, contributing with the first comparative quantitative proteomic analysis of the response of $S$. frugiperda cells to infection. The lack of an annotated genome sequence was overcome by cross-referencing to a database that included sequences of proteins from $S$. frugiperda and related insect species. The authors found new differentially expressed proteins related to energy metabolism, endoplasmic reticulum and oxidative stress during AcMNPV infection (Carinhas et al., 2011b). In particular, the up-regulation of two metabolic enzymes, PDH-E3 and ALDH, was observed, which account for an increased efficiency of the coupling of glycolysis and the TCA cycle and for the anaplerotic feeding of carboxylic acids, respectively. These observations go along with the increased metabolic fluxes of central carbon metabolism during baculovirus infection (Bernal et al., 2009), emphasizing the importance of energy metabolism during viral infection. Concerning the cellular stress response to infection, the authors observed a decrease in the levels of the chaperone ERp57 and the polypeptide transporter SRP57. Both proteins are effectors of the untranslated-protein response (UPR), and their down-regulation envisages the baculovirus capacity in avoiding the deleterious effects of cellular stress response.

Altogether, these results demonstrate that efficient replication of baculovirus depends on the capacity of viral manipulation of different cellular pathways, the control of which are needed for the success of viral infections.

Systems-level knowledge of baculovirus-host interactions requires an effort from the scientific community in the direction of insect cells/host genome sequencing. Recent efforts by Nguyen etal. (2012) succeeded in the transcriptome sequencing of $H$. zea cell line, providing a microarray platform to investigate baculovirus-insect cell interactions. Also, Xue et al. (2012) used next-generation sequencing to analyze differential gene expression following $B m \mathrm{NPV}$ infection of $B m 5$ cell line. A gene enrichment analysis showed that gene sets enclosing

\section{REFERENCES}

Aubert, M., and Blaho, J. A. (2001). Modulation of apoptosis during herpes simplex virus infection in human cells. Microbes Infect. 3, 859-866.

Avota, E., Gassert, E., and SchneiderSchaulies, S. (2011). Cytoskeletal dynamics: concepts in measles virus replication and immunomodulation. Viruses 3, 102-117.

Belyavskyi, M., Braunagel, S. C., and Summers, M. D. (1998). The structural protein ODV-EC27 of Autographa californica nucleopolyhedrovirus is a multifunctional viral cyclin. Proc. Natl. Acad. Sci. U.S.A.

Ben-Israel, H., and Kleinberger, T. (2002). Adenovirus and cell cycle D1395.

Bernal, V., Carinhas, N., Yokomizo, A. Y., Carrondo, M. J. T., and Alves, P. M. (2009). Cell density effect in the baculovirus-insect cells system: a quantitative analysis of energetic metabolism. Biotechnol. Bioeng. 104, 162-180.

Bernal, V., Monteiro, F., Carinhas, N., Ambrósio, R., and Alves, P. 95, 11205-11210. control. Front. Biosci. 7, D1369-

cytoskeleton, transcription, translation, energy metabolism, iron metabolism, and ubiquitin-proteasome pathways are altered during the course of baculovirus infection. The information gathered during transcriptional analysis was then used to define the interactome network between $B m \mathrm{NPV}$ and host proteins at a systems level, revealing direct interaction of viral proteins with cellular components, such as the proteasome, the cytoskeleton and the spliceosome (Xue et al., 2012).

\section{CONCLUSION}

Baculoviruses have developed several strategies to subvert the mechanisms of cellular defense against infection. In this fight, baculoviruses take control of cellular structures, such as the cytoskeleton, and trigger signaling responses leading to cell cycle arrest, induction of the DNA damage response, inhibition of apoptosis and intensification of energy metabolism. Although many of these responses are shared by different viruses, the specific characteristic features of the adaptations evolved by Baculoviruses have been highlighted in this review.

Although many studies concerning baculovirus molecular biology and the infection process have been pursued, there is a lack of a whole-system level integration of cross-platform reported data. Thus far, the application of high-throughput transcriptomic and proteomic approaches has been hampered by the current unavailability of lepidopteran genome sequences.

System-level proteomic studies can provide useful insights on the dynamic host response to infection. Indeed, the direct crosstalk between virus and host occurs mainly at the protein level. Viral proteins are major effectors on the subversion and manipulation of host cell physiology. Mapping such intricate network of interactions and, more importantly, deciphering their outcome at the cellular level, will provide a step-further in our current knowledge on the biological outcome of infection.

\section{ACKNOWLEDGMENTS}

This work was supported by the Portuguese Fundação para a Ciência e Tecnologia (FCT) through the Project PTDC/EBBEBI/103359/2008 and by the European Comission FP7, ComplexINC Project. Francisca Monteiro acknowledges FCT for her PhD fellowship grant (SFRH/BD/7013/2010), Nuno Carinhas for his post-doctoral fellowship grant (SFRH/BPD/80514), and Vicente Bernal acknowledges a postdoctoral contract from Universidad de Murcia (Programa Propio).

M. (2010). An integrated analysis of enzyme activities, cofactor pools and metabolic fluxes in baculovirus-infected Spodoptera frugiperda Sf9 cells. J. Biotechnol. 150, 332-342.

Bertin, J., Mendrysa, S. M., LaCount, D. J., Gaur, S., Krebs, J. F., Armstrong, R. C., etal. (1996). Apoptotic suppression by baculovirus P35 involves cleavage by and inhibition of a virusinduced CED-3/ICE-like protease. $J$. Virol. 70, 6251-6259.

Bideshi, D. K., Anwar, A. T., and Federici, B. A. (1999). A baculovirus anti-apoptosis gene homolog of the Trichoplusia ni granulovirus. Virus Genes 19, 95-101.

Birnbaum, M. J., Clem, R. J., and Miller, L. K. (1994). An apoptosis-inhibiting gene from a nuclear polyhedrosis virus encoding a polypeptide with Cys/His sequence motifs. J. Virol. 68, 2521-2528.

Blissard, G. W., and Rohrmann, G. F. (1991). Baculovirus gp64 gene expression: analysis of sequences modulating early transcription and transactivation by IE1. J. Virol. 65, 5820-5827. 
Blissard, G. W., and Wenz, J. R. (1992). Baculovirus gp64 envelope glycoprotein is sufficient to mediate $\mathrm{pH}$ dependent membrane fusion. J. Virol. $66,6829-6835$

Borden, K. L. (2000). RING domains: master builders of molecular scaffolds? J. Mol. Biol. 295, 1103-1112.

Braunagel, S. C., Guidry, P. A., Rosasacosta, G., Engelking, L., and Summers, M. A. X. D. (2001) Identification of BV/ODV-C42, an Autographa californica nucleopolyhedrovirus orf101-encoded structural protein detected in infected-cell complexes with ODV-EC27 and p78/83. J. Virol. 75, 12331-12338.

Braunagel, S. C., Parr, R., Belyavskyi, M., and Summers, M. D. (1998) Autographa californica nucleopolyhedrovirus infection results in Sf9 cell cycle arrest at G2/M phase. Virology 244, 195-211.

Bump, N. J., Hackett, M., Hugunin, M., Seshagiri, S., Brady, K., Chen, P., et al. (1995). Inhibition of ICE family proteases by baculovirus antiapoptotic protein p35. Science 269, 1885-1888.

Cantó, C., Gerhart-Hines, Z., Feige, J. N., Lagouge, M., Noriega, L., Milne, J. C., et al. (2009). AMPK regulates energy expenditure by modulating $\mathrm{NAD}+$ metabolism and SIRT1 activity. Nature 458, 1056-1060.

Carinhas, N., Bernal, V., Monteiro, F., Carrondo, M. J. T., Oliveira, R., and Alves, P. M. (2010). Improving baculovirus production at high cell density through manipulation of energy metabolism. Metab. Eng. 12, 39-52.

Carinhas, N., Bernal, V., Teixeira, A. P., Carrondo, M. J., Alves, P. M., and Oliveira, R. (2011a). Hybrid metabolic flux analysis: combining stoichiometric and statistical constraints to model the formation of complex recombinant products. BMC Syst. Biol. 5, 34. doi: 10.1186/ 1752-0509-5-34

Carinhas, N., Robitaille, A. M., Moes, S. Carrondo, M. J. T., Jenoe, P., Oliveira, R., et al. (2011b). Quantitative proteomics of Spodoptera frugiperda cells during growth and baculovirus infection. PLoS ONE 6, e26444. doi: 10.1371/journal.pone.0026444

Carpentier, D. C. J., Griffiths, C. M., and King, L. A. (2008). The baculovirus P10 protein of Autographa californica nucleopolyhedrovirus forms two distinct cytoskeletal-like structures and associates with polyhedral occlusion bodies during infection. Virology 371 , 278-291.

Carstens, E. B., Tjia, S. T., and Doerfler, W. (1979). Infection of Spodoptera frugiperda cells with Autographa californica nuclear polyhedrosis virus
I. Synthesis of intracellular proteins after virus infection. Virology 99, 386-398.

Charlton, C. A., and Volkman, L. E. (1993). Penetration of Autographa californica nuclear polyhedrosis virus nucleocapsids into IPLB Sf 21 cells induces actin cable formation. Virology 197, 245-254.

Charlton, C. A., and Volkman, L. E. (1991). Sequential rearrangement and nuclear polymerization of actin in baculovirus-infected Spodoptera frugiperda cells. J. Virol. 65, 1219 1227.

Chaurushiya, M. S., and Weitzman, M. D. (2010). Viral manipulation of DNA repair and cell cycle checkpoints. DNA Repair 8, 1166-1176.

Chen, A. Y., and Qiu, J. (2010). Parvovirus infection-induced cell death and cell cycle arrest. Fut. Virol. 5, 731-743.

Chen, H., Li, G., Huang, G., Chen, K., and Yao, Q. (2010). Characterization of ORF29 of Bombyx mor nucleopolyhedrovirus. Acta Virol. 275-280.

Clem, R. J. (2001). Baculoviruses and apoptosis: the good, the bad, and the ugly. Cell Death Differ. 8, 137-143.

Clem, R. J. (2005). The role of apoptosis in defense against baculovirus infection in insects. Curr. Top. Microbiol. Immunol. 289, 113-129.

Clem, R. J., Fechheimer, M., and Miller L. K. (1991). Prevention of apoptosis by a baculovirus gene during infection of insect cells. Science 254 1388-1390.

Clem, R. J., and Miller, L. K. (1994) Control of programmed cell death by the baculovirus genes p35 and iap. Mol. Cell. Biol. 14, 5212-5222.

Cooray, S. (2004). The pivotal role of phosphatidylinositol 3-kinase-Akt signal transduction in virus survival. J. Gen. Virol. 85, 1065-1076.

Crook, N. E., Clem, R. J., and Miller L. K. (1993). An apoptosis-inhibiting baculovirus gene with a zinc fingerlike motif. J. Virol. 67, 2168-2174.

Cudmore, S., Reckmann, I., and Way, M. (1997). Viral manipulations of the actin cytoskeleton. Trends Microbiol. $5,142-148$.

Davy, C., and Doorbar, J. (2007). G2/M cell cycle arrest in the life cycle of viruses. Virology 368, 219-226.

De, B. P., Lesoon, A., and Banerjee, a K. (1991). Human parainfluenza virus type 3 transcription in vitro: role of cellular actin in mRNA synthesis. $J$. Virol. 65, 3268-3275.

Deshaies, R. J., and Joazeiro, C. A. P. (2009). RING domain E3 ubiquitin ligases. Annu. Rev. Biochem. 78, 399-434.
Dowdy, S. F., Hinds, P. W., Louie, K., Reed, S. I., Arnold, A., and Weinberg, R. A. (1993). Physical interaction of the retinoblastoma protein with human D cyclins. Cell 73, 499-511.

Draetta, G., and Beach, D. (1989). The mammalian cdc2 protein kinase: mechanisms of regulation during the cell cycle. J. Cell Sci. Suppl. 12, 21-27.

Dreschers, S., Roncarati, R., and Knebel-mo, D. (2001). Actin rearrangement-inducing factor of baculoviruses is tyrosine phosphorylated and colocalizes to F-actin at the plasma membrane. J. Virol. 75, 3771-3778.

Du, Q., Lehavi, D., Faktor, O., Qi, Y., and Chejanovsky, N. (1999). Isolation of an apoptosis suppressor gene of the Spodoptera littoralis nucleopoly hedrovirus. J. Virol. 73, 1278-1285.

Du, X., and Thiem, S. M. (1997). Responses of insect cells to baculovirus infection: protein synthesis shutdown and apoptosis. J. Virol. 71 7866-7872.

Esfandiarei, M., Luo, H., Yanagawa, B., Suarez, A., Dabiri, D., Zhang, J., and McManus, B. M. (2004). Protein kinase $\mathrm{B} / \mathrm{Akt}$ regulates coxsackievirus B3 replication through a mechanism which is not caspase dependent. J. Virol. 78, 4289-4298.

Ewen, M. E., Sluss, H. K., Sherr, C. J., Matsushime, H., Kato, J., and Livingston, D. M. (1993). Functional interactions of the retinoblastoma protein with mammalian D type cyclins. Cell 73, 487-497.

Fang, M., Dai, X., and Theilmann, D. A. (2007). Autographa californica multiple nucleopolyhedrovirus EXON0 (ORF141) is required for efficient egress of nucleocapsids from the nucleus. J. Virol. 81, 9859-9869.

Fang, M., Nie, Y., Harris, S., Erlandson, M. A., and Theilmann, D. A. (2009a). Autographa californica multiple nucleopolyhedrovirus core gene ac96 encodes a per Os infectivity factor (PIF-4). J. Virol. 83, 12569-12578.

Fang, M., Nie, Y., and Theilmann, D. A. (2009b). AcMNPV EXON0 (AC141) which is required for the efficient egress of budded virus nucleocapsids interacts with beta-tubulin. Virology 385, 496-504.

Fang, M., Nie, Y., Wang, Q., Deng, F., Wang, R., Wang, H., et al. (2006). Open reading frame 132 of Helicoverpa armigera nucleopolyhedrovirus encodes a functional per os infectivity factor (PIF-2). J. Gen. Virol. 87, 2563-2569.

Faulkner, P., Kuzio, J., Williams, G. V., and Wilson, J. A. (1997). Analysis of p74, a PDV envelope protein of
Autographa californica nucleopolyhedrovirus required for occlusion body infectivity in vivo. J. Gen. Virol. 78( $\mathrm{Pt}$ 12), 3091-3100.

Fowler, V. M. (1990). Tropomodulin: a cytoskeletal protein that binds to the end of erythrocyte tropomyosin and inhibits tropomyosin binding to actin. J. Cell Biol. 111, 471-481.

Fujimoto, M., and Nakai, A. (2010). The heat shock factor family and adaptation to proteotoxic stress. FEBS J. 277, 4112-4125.

Furler, R. L., and Uittenbogaart, C. H. (2010). Signaling through the P38 and ERK pathways: a common link between HIV replication and the immune response. Immunol. Res. 48, 99-109.

Gandhi, K. M., Ohkawa, T., Welch, M. D., and Volkman, L. E. (2012). The nuclear localization of actin requires AC102 in Autographa californica M nucleopolyhedrovirus-infected cells. J. Gen. Virol. 93(Pt 8), 1795-803.

Gao, X., Wang, H., and Sairenji, T. (2004). Inhibition of EpsteinBarr virus (EBV) reactivation by short interfering RNAs targeting p38 mitogen-activated protein kinase or c-myc in EBV-positive epithelial cells. J. Virol. 78, 11798-11806.

Ge, J., Wei, Z., Huang, Y., Yin, J., Zhou, Z., and Zhong, J. (2007). AcMNPV ORF38 protein has the activity of ADP-ribose pyrophosphatase and is important for virus replication. Virology 361, 204-211.

Gidalevitz, T., Prahlad, V., and Morimoto, R. I. (2011). The stress of protein misfolding: from single cells to multicellular organisms. Cold Spring Harb. Perspect. Biol. 3, a009704.

Goley, E. D., Ohkawa, T., Mancuso, J., Woodruff, J. B., D'Alessio, J. A., Cande, W. Z., et al. (2006a). Dynamic nuclear actin assembly by Arp $2 / 3$ complex and a baculovirus WASPlike protein. Science 314, 464-467.

Goley, E. D., Ohkawa, T., Mancuso, J., Woodruff, J. B., D’Alessio, J. A., Cande, W.Z., et al. (2006b). Dynamic nuclear actin assembly by Arp $2 / 3$ complex and a baculovirus WASPlike protein. Science 314, 464-467.

Green, M. C., Monser, K. P., and Clem, R. J. (2004). Ubiquitin protein ligase activity of the anti-apoptotic baculovirus protein Op-IAP3. Virus Res. 105, 89-96.

Groschel, B., and Bushman, F. (2005). Cell cycle arrest in G2/M promotes early steps of infection by human immunodeficiency virus. J. Virol. 79, 5695-5704.

Grula, M. A., Buller, P. L., and Weaver, R. F. (1981), $\alpha$-Amanitin-resistant viral RNA synthesis in nuclei isolated from 
nuclear polyhedrosis virus-infected Heliothis zea larvae and Spodoptera frugiperda cells. J. Virol. 38, 916-921.

Guy, M. P., and Friesen, P. D. (2008). Reactive-site cleavage residues confer target specificity to baculovirus $\mathrm{P} 49$, a dimeric member of the P35 family of caspase inhibitors. J. Virol. 82 , 7504-7514.

Gyrd-Hansen, M., and Meier, P. (2010). IAPs: from caspase inhibitors to modulators of NF-kappaB, inflammation and cancer. Nat. Rev. Cancer 10, 561-574.

Haas, A. L., Katzung, D. J., Reback, P. M., and Guarino, L. A. (1996). Functional characterization of the ubiquitin variant encoded by the baculovirus Autographa californica. Biochemistry 35, 5385-5394.

Harrison, R. L., Sparks, W. O., and Bonning, B. C. (2010). Autographa californica multiple nucleopolyhedrovirus ODV-E56 envelope protein is required for oral infectivity and can be substituted functionally by Rachiplusia ou multiple nucleopolyhedrovirus ODV-E56. J. Gen. Virol. 91, 1173-1182.

Hinds, M. G., Norton, R. S., Vaux, D. L., and Day, C. L. (1999). Solution structure of a baculoviral inhibitor of apoptosis (IAP) repeat. Nat. Struct. Biol. 6, 648-651.

Holloszy, J. O., Oscai, L. B., Don, I. J., and Molé, P. A. (1970). Mitochondrial citric acid cycle and related enzymes: adaptive response to exercise. Biochem. Biophys. Res. Commun. 40, 1368-1373.

Horton, H. M., and Burand, J. P. (1993). Saturable attachment sites for polyhedron-derived baculovirus on insect cells and evidence for entry via direct membrane fusion. J. Virol. 67, 1860-1868.

Huang, N., Wu, W., Yang, K., Passarelli, A. L., Rohrmann, G. F., and Clem, R. J. (2011). Baculovirus infection induces a DNA damage response that is required for efficient viral replication. J. Virol. 85, 12547-12556.

Ikeda, M., and Kobayashi, M. (1999). Cell-cycle perturbation in Sf9 cells infected with Autographa californica nucleopolyhedrovirus. Virology 258, 176-188.

Ikonomou, L., Schneider, Y.-J., and Agathos, S. N. (2003). Insect cell culture for industrial production of recombinant proteins. Appl. Microbiol. Biotechnol. 62, 1-20.

Imai, N., Matsuda, N., Tanaka, K. Nakano, A., Matsumoto, S., and Kang, W. (2003). Ubiquitin ligase activities of Bombyx mori nucleopolyhedrovirus RING finger proteins. J. Virol. 77, 923-930.
Iwanaga, M., Shimada, T., Kobayashi, M., and Kang, W. (2007). Identification of differentially expressed host genes in Bombyx mori nucleopolyhedrovirus infected cells by using subtractive hybridization. Appl. Entomol. Zool. 42, 151-159.

Iwanaga, M., Takaya, K., Katsuma, S., Ote, M., Tanaka, S., Kamita, S. G., et al. (2004). Expression profiling of baculovirus genes in permissive and nonpermissive cell lines. Biochem. Biophys. Res. Commun. 323, 599-614.

Ji, W.-T., and Liu, H. J. (2008). PI3K-Akt signaling and viral infection. Recent Pat. Biotechnol. 2, 218-226.

Johnson, G. L., and Lapadat, R. (2002). Mitogen-activated protein kinase pathways mediated by ERK, JNK, and p38 protein kinases. Science 298, 1911-1912.

Johnson, R. A., Wang, X., Ma, X. L., Huong, S. M., and Huang, E. S. (2001). Human cytomegalovirus upregulates the phosphatidylinositol 3kinase (PI3-K) pathway: inhibition of PI3-K activity inhibits viral replication and virus-induced signaling. $J$. Virol. 75, 6022-6032.

Kamen, A. A., Bédard, C., Tom, R. Perret, S., and Jardin, B. (1996). On-line monitoring of respiration in recombinant-baculovirus infected and uninfected insect cell bioreactor cultures. Biotechnol. Bioeng. 50, 36-48.

Kamita, S., and Majima, K. (1993). Identification and characterization of the p35 gene of Bombyx mori nuclear polyhedrosis virus that prevents virus-induced apoptosis. J. Virol. 67, 455-463.

Kasman, L. M., and Volkman, L. E. (2000). Filamentous actin is required for lepidopteran nucleopolyhedrovirus progeny production. J. Gen. Virol. 81, 1881-1888.

Katsuma, S., Kawaoka, S., Mita, K., and Shimada, T. (2008). Genome-wide survey for baculoviral host homologs using the Bombyx genome sequence. Insect Biochem. Mol. Biol. 38, 10801086.

Katsuma, S., Mita, K., and Shimada, T. (2007). ERK- and JNKdependent signaling pathways contribute to Bombyx mori nucleopolyhedrovirus infection. J. Virol. 81, 13700-13709.

Katsuma, S., Tsuchida, A., MatsudaImai, N., Kang, W., and Shimada, T. (2011). Role of the ubiquitinproteasome system in Bombyx mori nucleopolyhedrovirus infection. $J$. Gen. Virol. 92, 699-705.

Keddie, B., Aponte, G., and Volkman, L. (1989). The pathway of infection of Autographa californica nuclear polyhedrosis virus in an insect host. Science 243, 1728-1730.

Kerr, J. F., Wyllie, A. H., and Currie, A R. (1972). Apoptosis: a basic biological phenomenon with wide-ranging implications in tissue kinetics. $B r . J$. Cancer 26, 239-257.

Kikhno, I., Gutiérrez, S., Croizier L., Croizier, G., and Ferber, M. L. (2002). Characterization of pif, a gene required for the per os infectivity of Spodoptera littoralis nucleopolyhedrovirus. J. Gen. Virol. 83, 3013-3022.

Kimberly, L., Schultz, W., and Friesen, P. D. (2009). Baculovirus DNA replication-specific expression factors trigger apoptosis and shutoff of host protein synthesis during infection. J. Virol. 83, 11123-11132.

Koyama, A. H., Fukumori, T., Fujita, M., Irie, H., and Adachi, A. (2000). Physiological significance of apoptosis in animal virus infection. Microbes Infect. 2, 1111-1117.

LaCount, D. J., and Friesen, P. D. (1997). Role of early and late replication events in induction of apoptosis by baculoviruses. J. Virol. 71, 1530-1537.

Lau, A., Swinbank, K. M., Ahmed, P. S., Taylor, D. L., Jackson, S. P., Smith, G C. M., et al. (2005). Suppression of HIV-1 infection by a small molecule inhibitor of the ATM kinase. Nat. Cell Biol. 7, 493-500.

Lehman, J. M., Laffin, J., and Friedrich, T. D. (1994). DNA content distribution of mouse cells following infection with polyoma virus. Cytometry 16, 138-143

Lehman, J. M., Laffin, J., and Friedrich, T. D. (2000). Simian virus 40 induces multiple $S$ phases with the majority of viral DNA replication in the G2 and second S phase in CV-1 cells. Exp. Cell Res. 258, 215-222.

Li, K., Wang, Y., Bai, H., Wang, Q. Song, J., Zhou, Y., et al. (2010). The putative pocket protein binding site of Autographa californica nucleopolyhedrovirus BV/ODV-C42 is required for virus-induced nuclear actin polymerization. J. Virol. 84, 7857-7868.

Li, L., Gu, B., Zhou, F., Chi, J., Wang, F., Liu, G., et al. (2012). Human herpesvirus $6 \mathrm{~A}$ infects human embryonic fibroblasts and induces $\mathrm{G} 2 / \mathrm{M}$ arrest and cell death. J. Med. Virol. 84, 657-663.

Lilley, C. E., Carson, C. T., Muotri, A. R., Gage, F. H., and Weitzman, M D. (2005). DNA repair proteins affect the lifecycle of herpes simplex virus 1. Proc. Natl. Acad. Sci. U.S.A. 102 , 5844-5849.

Liu, X., Chen, K., Cai, K., and Yao Q. (2008). Determination of protein composition and host-derived proteins of Bombyx mori nucleopolyhedrovirus by 2-dimensional electrophoresis and mass spectrometry. Intervirology 51, 369-376.

Long, G., Pan, X., Kormelink, R., and Vlak, J. M. (2006). Functional entry of baculovirus into insect and mammalian cells is dependent on clathrinmediated endocytosis. J. Virol. 80, 8830-8833.

Lu, A., and Carstens, E. B. (1993). Immediate-early baculovirus genes transactivate the p143 gene promoter of Autographa californica nuclear polyhedrosis virus. Virology 195, 710-718.

Lu, S., Ge, G., and Qi, Y. (2004). Ha-VP39 binding to actin and the influence of F-actin on assembly of progeny virions. Arch. Virol. 149, 2187-2198.

Luo, H., Yanagawa, B., Zhang, J., Luo, Z., Zhang, M., Esfandiarei, M., et al. (2002). Coxsackievirus B3 replication is reduced by inhibition of the extracellular signal-regulated kinase (ERK) signaling pathway. J. Virol. 76, 3365-3373.

Lyupina, Y. V., Dmitrieva, S. B., Timokhova, A. V., Beljelarskaya, S. N., Zatsepina, O. G., Evgen'ev, M. B., et al. (2010). An important role of the heat shock response in infected cells for replication of baculoviruses. Virology 406, 336-341.

Lyupina, Y. V., Zatsepina, O. G., Timokhova, A. V., Orlova, O. V., Kostyuchenko, M. V., Beljelarskaya, S. N., et al. (2011). New insights into the induction of the heat shock proteins in baculovirus infected insect cells. Virology 421, 34-41.

Ma, Y.-B., and Chang, H.-Y. (2011). Caspase work model during pathogen infection. Virol. Sin. 26, 366-375.

Machesky, L. M., Insall, R. H., and Volkman L. E. (2001). WASP homology sequences in baculoviruses. Trends Cell Biol. 11, 286-287.

de Magalhães, J. C., Andrade, A. A., Silva, P. N., Sousa, L. P., Ropert, C., Ferreira, P. C., et al. (2001). A mitogenic signal triggered at an early stage of vaccinia virus infection: implication of MEK/ERK and protein kinase A in virus multiplication. J. Biol. Chem. 276, 38353-38360.

Maguire, T., Harrison, P., Hyink, O., Kalmakoff, J., and Ward, V. K. (2000). The inhibitors of apoptosis of Epiphyas postvittana nucleopolyhedrovirus. J. Gen. Virol. 81, 28032811.

Manji, G. A., Hozak, R. R., LaCount, D. J., and Friesen, P. D. (1997). Baculovirus inhibitor of apoptosis functions at or upstream of the 
apoptotic suppressor P35 to prevent programmed cell death. J. Virol. 71, 4509-4516.

Marek, M., Merten, O.-W., FrancisDevaraj, F., and Oers, M. M. V. (2012). Essential C-terminal region of the baculovirus minor capsid protein VP80 binds DNA. J. Virol. 86, 1728-1738.

Mayer, M. P. (2005). Recruitment of Hsp70 chaperones: a crucial part of viral survival strategies. Rev. Physiol. Biochem. Pharmacol. 153, 1-46.

Maynard, N. D., Gutschow, M. V., Birch, E. W., and Covert, M. W. (2010). The virus as metabolic engineer. Biotechnol. J. 5, 686-694.

Merrington, C. L., Bailey, M. J., and Possee, R. D. (1997). Manipulation of baculovirus vectors. Mol. Biotechnol. 8, 283-297.

Milks, M. L., Washburn, J. O., Willis, L. G., Volkman, L. E., and Theilmann D. A. (2003). Deletion of pe38 attenuates AcMNPV genome replication, budded virus production, and virulence in Heliothis virescens. Virology 310, 224-234.

Miller, L. K (ed.). (1997). The Baculoviruses. New York: Springer.

Miller, L. K. (1999). An exegesis of IAPs: salvation and surprises from BIR motifs. Trends Cell Biol. 9, 323-328.

Morgan, D. O. (1995). Principles of CDK regulation. Nature 374, 131134

Munger, J., Bajad, S. U., Coller, H. a, Shenk, T., and Rabinowitz, J. D. (2006). Dynamics of the cellular metabolome during human cytomegalovirus infection. PLoS Pathog. 2, e132. doi: 10.1371/ journal.ppat.0020132

Munger, J., Bennett, B. D., Parikh, A., Feng, X.-J., Rabitz, H. A., Shenk, T., et al. (2010). Systems-level metabolic flux profiling identifies fatty acid synthesis as a target for antiviral therapy. Nat. Biotechnol. 26, 1179-1186.

van Munster, M., Willis, L. G., Elias, M., Erlandson, M. A., Brousseau, R., Theilmann, D. A., et al. (2006). Analysis of the temporal expression of Trichoplusia ni single nucleopolyhedrovirus genes following transfection of BT1-Tn-5B1-4 cells. Virology 354, 154-166.

Nagy, P. D., Wang, R. Y., Pogany, J., Hafren, A., and Makinen, K. (2011). Emerging picture of host chaperone and cyclophilin roles in RNA virus replication. Virology 411, 374-382.

Nguyen, Q., Palfreyman, R. W., Chan, L. C. L., Reid, S., and Nielsen, L. K. (2012). Transcriptome sequencing of and microarray development for a Helicoverpa zea cell line to investigate in vitro insect cell-baculovirus interactions. PLOS ONE 7, e36324. doi: 10.1371/journal.pone.0036324

Nobiron, I. (2003). Autographa californica nucleopolyhedrovirus infection of Spodoptera frugiperda cells: a global analysis of host gene regulation during infection, using a differential display approach. J. Gen. Virol. 84, 3029-3039.

Nurse, P. (1994). Ordering S phase and $\mathrm{M}$ phase in the cell cycle. Cell 79 547-550.

van Oers, M. M. (2011). Opportunities and challenges for the baculovirus expression system. J. Invertebr. Pathol. 107(Suppl.) S3-S15.

Ohkawa, T., Rowe, A. R., and Volkman, L. E. (2002). Identification of six Autographa californica multicapsid nucleopolyhedrovirus early genes that mediate nuclear localization of G-actin. J. Virol. 76, 12281-12289.

Ohkawa, T., and Volkman, L. E. (1999). Nuclear F-actin is required for AcMNPV nucleocapsid morphogenesis. Virology 264, 1-4.

Ohkawa, T., Volkman, L. E., and Welch, M. D. (2010). Actin-based motility drives baculovirus transit to the nucleus and cell surface. J. Cell Biol. 190, 187-195.

Ohkawa, T., Washburn, J. O., Sitapara, R., Sid, E., and Volkman, L. E. (2005). Specific binding of Autographa californica $\mathrm{M}$ nucleopolyhedrovirus occlusion-derived virus to midgut cells of Heliothis virescens larvae is mediated by products of pif genes Ac119 and Ac022 but not by Ac115. J. Virol. 79, 15258-15264.

Op De Beeck, A., and Caillet-Fauquet, P. (1997). Viruses and the cell cycle. Prog. Cell Cycle Res. 3, 1-19.

Palomares, L. A., López, S., and Ramírez, O. T. (2004). Utilization of oxygen uptake rate to assess the role of glucose and glutamine in the metabolism of infected insect cell cultures. Biochem. Eng. J. 19, 87-93.

Passarelli, A. L., and Guarino, L. A. (2007). Baculovirus late and very late gene regulation. Curr. Drug Targets 8 , 1103-1115.

Passarelli, A. L., and Miller, L. K. (1993). Three baculovirus genes involved in late and very late gene expression: ie-1, ie-n, and lef-2. J. Virol. 67, 2149-2158.

Passarelli, A. L. (2012). Barriers to success: how baculoviruses establish efficient systemic infections. Virology 411, 383-392.

Pei, Z., Reske, G., Huang, Q., Hammock, B. D., Qi, Y., and Chejanovsky, N. (2002). Characterization of the apoptosis suppressor protein P49 from the Spodoptera littoralis nucleopolyhedrovirus. J. Biol. Chem. 277, 48677-48684.

Pijlman, G. P., Pruijssers, A. J., and Vlak, J. M. (2003). Identification of pif-2, a third conserved baculovirus gene required for per os infection of insects. J. Gen. Virol. 84, 20412049.

Polyak, K., Kato, J. Y., Solomon, M. J., Sherr, C. J., Massague, J., Roberts, J. M., et al. (1994). p27Kip1, a cyclinCdk inhibitor, links transforming growth factor-beta and contact inhibition to cell cycle arrest. Genes Dev. 8, 9-22.

Popham, H. J. R., Grasela, J. J., Goodman, C. L., and McIntosh, A. H. (2010). Baculovirus infection influences host protein expression in two established insect cell lines. J. Insect Physiol. 56, 1237-1245.

Possee, R. D. (1993). Baculovirus expression vectors - a laboratory manual. Trends Biotechnol. 11, 267-268.

Qin, D., Feng, N., Fan, W., Ma, X., Yan, Q., Lv, Z., et al. (2011). Activation of PI3K/AKT and ERK MAPK signal pathways is required for the induction of lytic cycle replication of Kaposi's sarcoma-associated herpesvirus by herpes simplex virus type 1. BMC Microbiol. 11, 240. doi: 10.1186/1471-2180-11-240

Reilly, L. M., and Guarino, L. A. (1994). The pk-1 gene of Autographa californica multinucleocapsid nuclear polyhedrosis virus encodes a protein kinase. J. Gen. Virol. 75 (Pt 11) 2999-3006.

Reilly, L. M., and Guarino, L. A. (1996). The viral ubiquitin gene of Autographa californica nuclear polyhedrosis virus is not essential for viral replication. Virology 218, 243-247.

Roberts, K. L., and Baines, J. D. (2011). Actin in herpesvirus infection. Viruses 3, 336-346.

Rohrmann, G. F. (2011). “The AcMNPV genome: gene content, conservation, and function," in Baculovirus Molecular Biology, 2nd Edn, ed. G. F. Rohrmann (Bethesda, MD: National Center for Biotechnology Information), 2-23.

Roncarati, R., and Knebel-Mörsdorf, D. (1997). Identification of the early actin-rearrangement-inducing factor gene, arif-1, from Autographa califor nica multicapsid nuclear polyhedrosis virus. J. Virol. 71, 7933-7941.

Sagisaka, A., Fujita, K., Nakamura, Y., Ishibashi, J., Noda, H., Imanishi, S., etal. (2010). Genomewide analysis of host gene expression in the silkworm cells infected with Bombyx mori nucleopolyhedrovirus. Virus Res. 147, 166-175.
Sakai, K., Barnitz, R. A., ChaigneDelalande, B., Bidère, N., and Lenardo, M. J. (2011). Human immunodeficiency virus type 1 Vif causes dysfunction of Cdk1 and CyclinB1: implications for cell cycle arrest. Virol. J. 8, 219.

Salem, T. Z., Zhang, F., Xie, Y., and Thiem, S. M. (2011). Comprehensive analysis of host gene expression in Autographa californica nucleopolyhedrovirus-infected Spodoptera frugiperda cells. Virology 412, 167-178.

Salvesen, G. S., and Duckett, C. S. (2002). IAP proteins: blocking the road to death's door. Nat Rev. Mol. Cell Biol. 3, 401-410.

Seshagiri, S., and Miller, L. K. (1997). Baculovirus inhibitors of apoptosis (IAPs) block activation of Sf-caspase1. Proc. Natl. Acad. Sci. U.S.A. 94, 13606-13611.

Seviour, E. G., and Lin, S. -Y. (2010). The DNA damage response: balancing the scale between cancer and ageing. Aging 2, 900-907.

Shen, H., and Chen, K. (2012). BM61 of Bombyx mori nucleopolyhedrovirus: its involvement in the egress of nucleocapsids from the nucleus. FEBS Lett. 586, 990-995.

Shin, Y.-K., Liu, Q., Tikoo, S. K., Babiuk, L. A., and Zhou, Y. (2007). Effect of the phosphatidylinositol 3kinase/Akt pathway on influenza A virus propagation. J. Gen. Virol. 88, 942-950.

Sparks, W. O., Harrison, R. L., and Bonning, B. C. (2011). Autographa californica multiple nucleopolyhedrovirus ODV-E56 is a per os infectivity factor, but is not essential for binding and fusion of occlusion-derived virus to the host midgut. Virology 409, 69-76.

Spink, K. M., and Fluck, M. M. (2003). Polyomavirus hr-t mutantspecific induction of a G2/M cellcycle arrest that is not overcome by the expression of middle $\mathrm{T}$ and/or small T. Virology 307, 191-203.

Stillman, B. (1996). Cell cycle control of DNA replication. Science 274, 1659-1664.

Stolp, B., and Fackler, O. T. (2011). How HIV takes advantage of the cytoskeleton in entry and replication. Viruses 3, 293-311.

Strauss, E. J. (1996). Intracellular pathogens: a virus joins the movement. Curr. Biol. 6, 504-507.

Summers, M. D., and Arnott, H. J. (1969). Ultrastructural studies on inclusion formation and virus occlusion in nuclear polyhedrosis and granulosis virus-infected cells of Trichoplusia ni (Hübner). J. Ultrastruct. Res. 28, 462-480. 
Terry, L. J., Vastag, L., Rabinowitz, J. D., and Shenk, T. (2012). Human kinome profiling identifies a requirement for AMP-activated protein kinase during human cytomegalovirus infection. Proc. Natl. Acad. Sci. U.S.A. 109 , 3071-3076.

Tong, L., and Denu, J. M. (2010). Function and metabolism of sirtuin metabolite $O$-acetyl-ADPribose. Biochim. Biophys. Acta 1804, 1617-1625.

Tyers, M., and Willems, A. R. (1999). One ring to rule a superfamily of E3 ubiquitin ligases. Science 284, 601, 603-604.

Volkman, L. E. (1988). Autographa californica MNPV nucleocapsid assembly: inhibition by cytochalasin D. Virology 163, 547-553.

Volkman, L. E. (1997). Nucleopolyhedrovirus interactions with their insect hosts. Adv. Virus Res. 48, 313-348.

Vucic, D., Kaiser, W. J., Harvey, A. J., and Miller, L. K. (1997). Inhibition of reaper-induced apoptosis by interaction with inhibitor of apoptosis proteins (IAPs). Proc. Natl. Acad. Sci. U.S.A. 94, 10183-10188.

Vucic, D., Kaiser, W. J., and Miller, L. K. (1998a). A mutational analysis of the baculovirus inhibitor of apoptosis Op-IAP. J. Biol. Chem. 273, 33915-33921.

Vucic, D., Kaiser, W. J., and Miller, L. K. (1998b). Inhibitor of apoptosis proteins physically interact with and block apoptosis induced by Drosophila proteins HID and GRIM. Mol. Cell. Biol. 18, 3300-3309.

Wang, P., and Granados, R. R. (1997). An intestinal mucin is the target substrate for a baculovirus enhancin. Proc. Natl. Acad. Sci. U.S.A. 94, 6977-6982.

Wang, Y., Wang, Q., Liang, C., Song, J., Li, N., Shi, H., et al.
(2008). Autographa californica multiple nucleopolyhedrovirus nucleocapsid protein BV/ODV-C42 mediates the nuclear entry of P78/83. J. Virol. 82, 4554-4561.

Washburn, J. O., Chan, E. Y., Volkman, L. E., Jared, J., Jarvis, D. L., and Aumiller, J. J. (2003). Early synthesis of budded virus envelope fusion protein GP64 enhances Autographa californica multicapsid nucleopolyhedrovirus virulence in orally infected Heliothis virescens. J. Virol. 77, 280-290.

Welch, M. D., and Mullins, R. D. (2002). Cellular control of actin nucleation. Annu. Rev. Cell Dev. Biol. 18, 247-288.

Willems, L., Tamburini, J., Chapuis, N., Lacombe, C., Mayeux, P., and Bouscary, D. (2012). PI3K and mTOR signaling pathways in cancer: new data on targeted therapies. Curr. Oncol. Rep. 14, 129-138.

Wright, C. W., and Clem, R. J. (2002) Sequence requirements for Hid binding and apoptosis regulation in the baculovirus inhibitor of apoptosis Op-IAP. Hid binds Op-IAP in a manner similar to Smac binding of XIAP. J. Biol. Chem. 277, 2454-2462.

Xia, Q., Zhou, Z., Lu, C., Cheng, D., Dai, F., Li, B., et al. (2004). A draft sequence for the genome of the domesticated silkworm (Bombyx mori). Science 306, 1937-1940.

Xiao, A., Wong, J., and Luo, H. (2010). Viral interaction with molecular chaperones: role in regulating viral infection. Arch. Virol. 155, 10211031.

Xiao, W., Yang, Y., Weng, Q., Lin, T., Yuan, M., Yang, K., et al. (2009). The role of the PI3K-Akt signal transduction pathway in Autographa californica multiple nucleopolyhedrovirus infection of Spodoptera frugiperda cells. Virology 391, 83-89.

Xu, G., Cirilli, M., Huang, Y., Rich, R. L., Myszka, D. G., and Wu, H. (2001). Covalent inhibition revealed by the crystal structure of the caspase-8/p35 complex. Nature 410, 494-497.

$\mathrm{Xu}$, H., Yao, L., Lu, S., and Qi, Y. (2007). Host filamentous actin is associated with Heliothis armigera single nucleopolyhedrosis virus (HaSNPV) nucleocapsid transport to the host nucleus. Curr. Microbiol. 54, 199-206.

Xue, J., Qiao, N., Zhang, W., Cheng, R.-L., Zhang, X.-Q., Bao, Y.-Y., et al. (2012). Dynamic interactions between Bombyx mori nucleopolyhedrovirus and its host cells revealed by transcriptome analysis. J. Virol. 86, 7345-7359.

Yamagishi, J., Isobe, R., Takebuchi, T., and Bando, H. (2003). DNA microarrays of baculovirus genomes: differential expression of viral genes in two susceptible insect cell lines. Arch. Virol. 148, 587-597.

Yang, Y., Fang, S., Jensen, J. P., Weissman, A. M., and Ashwell, J. D. (2000). Ubiquitin protein ligase activity of IAPs and their degradation in proteasomes in response to apoptotic stimuli. Science 288, 874-877.

Yuan, M., Huang, Z., Wei, D., Hu, Z., Yang, K., and Pang, Y. (2011). Identification of Autographa californica nucleopolyhedrovirus ac93 as a core gene and its requirement for intranuclear microvesicle formation and nuclear egress of nucleocapsids. J. Virol. 85, 11664-11674.

Zhao, X., Madden-fuentes, R. J., Lou, B. X., Pipas, J. M., Gerhardt, J., Rigell, C. J., et al. (2008). Ataxia telangiectasiamutated damage-signaling kinaseand proteasome-dependent destruction of Mre11-Rad50-Nbs1 subunits in Simian virus 40 -infected primate cells. J. Virol. 82, 5316-5328.

Zheng, Y., Li, J., Johnson, D. L., and Ou, J.-H. (2003). Regulation of hepatitis $\mathrm{B}$ virus replication by the ras-mitogen-activated protein kinase signaling pathway. J. Virol. 77, 77077712.

Zoog, S. J., Schiller, J. J., Wetter, J. A., Chejanovsky, N., and Friesen, P. D. (2002). Baculovirus apoptotic suppressor $\mathrm{P} 49$ is a substrate inhibitor of initiator caspases resistant to P35 in vivo. EMBO J. 21, 5130-5140.

Conflict of Interest Statement: The authors declare that the research was conducted in the absence of any commercial or financial relationships that could be construed as a potential conflict of interest.

Received: 06 July 2012; accepted: 23 October 2012; published online: 09 November 2012.

Citation: Monteiro F, Carinhas N, Carrondo MJT, Bernal $V$ and Alves PM (2012) Toward system-level understanding of baculovirus-host cell interactions: from molecular fundamental studies to large-scale proteomics approaches. Front. Microbio. 3:391. doi: 10.3389/ fmicb.2012.00391

This article was submitted to Frontiers in Virology, a specialty of Frontiers in Microbiology.

Copyright () 2012 Monteiro, Carinhas, Carrondo, Bernal and Alves. This is an open-access article distributed under the terms of the Creative Commons Attribution License, which permits use, distribution and reproduction in other forums, provided the original authors and source are credited and subject to any copyright notices concerning any thirdparty graphics etc. 